\title{
Adipocyte JAK2 mediates aging-associated metabolic liver disease and progression to hepatocellular carcinoma
}

Kevin C. Corbit ${ }^{1}$, Camella G. Wilson ${ }^{1}$, Dylan Lowe ${ }^{1}$, Jennifer L. Tran ${ }^{1}$, Nicholas B. Vera ${ }^{3}$, Michelle Clasquin ${ }^{3}$, Aras N. Mattis ${ }^{2,4}$, Ethan J. Weiss ${ }^{1,4}$

${ }^{1}$ Cardiovascular Research Institute

${ }^{2}$ Department of Pathology, University of California, San Francisco, CA USA

${ }^{3}$ Pfizer Global Research and Development, Cambridge Laboratories, Pfizer Inc., Cambridge, MA USA

${ }^{4}$ To whom correspondence should be addressed:

Ethan J. Weiss

555 Mission Bay Blvd South, Room 382Y

San Francisco, CA USA 94158

+1 415-514-0819

Ethan.Weiss@ucsf.edu

Aras N. Mattis

513 Parnassus Avenue, Room HSW-516

University of California, San Francisco

San Francisco, CA USA 94141

+1415 514-3062 
bioRxiv preprint doi: https://doi.org/10.1101/681809; this version posted June 24,2019 . The copyright holder for this preprint (which was not certified by peer review) is the author/funder. All rights reserved. No reuse allowed without permission.

Aras.Mattis@ucsf.edu

\section{Conflict of interest statement}

N. B. V. and M. C. are employees and shareholders of Pfizer, Inc. 


\section{ABSTRACT}

Non-alcoholic fatty liver disease (NAFLD) and steatohepatitis (NASH) are liver manifestations of the metabolic syndrome and can progress to hepatocellular carcinoma (HCC). Loss of Growth Hormone $(\mathrm{GH})$ signaling is reported to predispose to NAFLD and $\mathrm{NASH}$ through direct actions on the liver. Here, we report that aged mice lacking hepatocyte Jak2 (JAK2L), an obligate transducer of Growth Hormone (GH) signaling, spontaneously develop the full spectrum of phenotypes found in patients with metabolic liver disease, beginning with insulin resistance and lipodystrophy and manifesting as NAFLD, NASH and even HCC, independent of dietary intervention. Remarkably, insulin resistance, metabolic liver disease, and carcinogenesis are prevented in JAK2L mice via concomitant deletion of adipocyte Jak2 (JAK2LA). Further, we demonstrate that GH increases hepatic lipid burden but does so indirectly via signaling through adipocyte JAK2. Collectively, these data establish adipocytes as the mediator of $\mathrm{GH}$-induced metabolic liver disease and carcinogenesis. In addition, we report a new spontaneous model of NAFLD, NASH, and HCC that recapitulates the natural sequelae of human insulin resistance-associated disease progression. The work presented here suggests a attention be paid towards inhibition of adipocyte $\mathrm{GH}$ signaling as a therapeutic target of metabolic liver disease. 


\section{INTRODUCTION}

The global prevalence of NAFLD, a state of excess liver lipid accumulation in the absence of chronic alcohol intake, is estimated to be $\sim 24 \%$ (1). A subset of patients with NAFLD go on to develop non-alcoholic steatohepatitis (NASH) with associated inflammation and fibrosis. NASH is now the leading cause of liver transplantation in the United States and predisposes to HCC (2), the most common malignancy of liver worldwide (3). Currently, there are no FDA-approved treatments for $\mathrm{NASH}$, which could be a reflection of the lack of faithful animal models that fully recapitulate its clinical presentation $(4,5)$.

NASH pathogenesis is complex and multi-factorial, though the risk factors are nearly identical to those predisposing to the metabolic syndrome (4). It was revealed nearly two decades ago that NAFLD is significantly associated with insulin resistance (IR) (6), and NAFLD-associated hepatic IR is independent of adiposity and glucose intolerance (7). While the association of IR with fatty liver is strong, the cause-and-effect relationship is unclear. Hepatic fat content results from a balance of fatty acid influx, de novo lipogenesis (DNL), secretion of triglycerides, and catabolism of fatty acids by beta-oxidation (8). Given that these four processes occur within the liver itself, the majority of research and treatment paradigms for NAFLD, NASH, and HCC have been focused on liver intrinsic mechanisms.

How IR promotes hepatic lipid accumulation is debated. Insulin suppresses gluconeogenesis and induces DNL in liver (9). Thus, the predicted consequence of IR is increased glucose production and reduced lipogenesis. However, it is well recognized 
that the former and not latter pathways are affected in diabetics, as high levels of gluconeogenesis co-exist with increased hepatic lipid burden in the setting of IR. This phenomenon has been termed 'selective insulin resistance' and been attributed to both liver-intrinsic and -extrinsic mechanisms $(10,11)$.

Prolonged fasting/starvation, such as in anorexia nervosa (AN), and lipodystrophy (LD) are other conditions are also associated with fatty liver $(12,13)$. Interestingly, these states of adipose tissue dysfunction have IR as a commonality and, especially in the case of LD, have biochemical features more closely aligned with prevalent forms of IR than those caused by defects in insulin signaling itself (13). This suggests that adipose tissue dysfunction may be a common feature, and possible a driver, of various form of IR.

As is the case with protracted fasting, NAFLD and NASH are associated with adipose tissue dysfunction $(13,14)$. $\mathrm{GH}$ is a starvation-induced hormone that controls hepatic (and circulating) IGF1 levels and adipose tissue lipolysis during fasting $(15,16)$ and is elevated in LD patients (17). Malnutrition, LD, AN, and NAFLD are associated with hepatic GH resistance, which may seem paradoxical, but in fact hepatic $\mathrm{GH}$ resistance leads to elevated circulating $\mathrm{GH}$, via loss of IGF1-mediated feedback inhibition, which can act on non-liver, GH-responsive tissues. In fact, treatment of AN patients with $\mathrm{GH}$ indeed fails to increase insulin-like growth factor (IGF1) levels, confirming hepatic GH resistance, but does further decrease fat mass, indicating that adipose tissue remains $\mathrm{GH}$ responsive in the clinically $\mathrm{GH}$ 'resistant' state (18). Thus, elevated $\mathrm{GH}$ activity on adipose tissue 
may be a commonality among $\mathrm{GH}$ resistant and IR states, including starvation, LD, NAFLD/NASH.

$\mathrm{GH}$ is a major regulator of glucose and lipid metabolism $(19,20)$. Congenital loss of global GH signaling increases insulin sensitivity and adiposity and may decrease the incidence of diabetes and cancer $(21,22)$. Conversely, exposure to GH acutely (19) or chronically, in the setting of acromegaly, induces insulin resistance (23). Somewhat paradoxically, adult-onset of GH deficiency also predisposes to fatty liver and NASH (24), possibly by a different mechanism via direct effects on hepatic DNL (25). However, a unifying model of how GH impinges on insulin sensitivity to mediate glucose and lipid metabolism has not been universally accepted.

We previously reported that mice with hepatic $\mathrm{GH}$ resistance, via hepatocyte-specific deletion of Jak2 (JAK2L), developed fatty liver in a GH-dependent manner and had early signs of NASH by 20 -weeks of age (26). Here, we report that aged JAK2L mice are insulin resistant, lipodystrophic, and subsequently develop severe NASH and HCC. These phenotypes recapitulate the features of metabolic liver disease and are entirely dependent on adipocyte JAK2, as mice lacking both hepatocyte and adipocyte Jak2 (JAK2LA) retain insulin sensitivity and maintain liver homeostasis. Treatment with recombinant $\mathrm{GH}$ increases liver tri- (TAG) and di-acylglycerol (DAG) levels in control but not in mice lacking adipocyte Jak2 only. Collectively, we demonstrate that adipocytes are the target of $\mathrm{GH}$-induced changes in liver metabolism. Further, we provide a new model of metabolic liver disease that is independent of dietary intervention. 


\section{RESULTS}

Hepatic $\mathrm{GH}$ resistance promotes age-associated insulin resistance via adipocyte signaling. We aged cohorts of control ( $\mathrm{CON}, \mathrm{N}=16)$, JAK2L $(\mathrm{N}=14)$, and JAK2LA ( $\mathrm{N}=17)$ mice to between 70-75 weeks of age and determined glucose homeostasis in the fed and fasted states. Similar to our previous results in younger mice (27), induction of hepatic $\mathrm{GH}$ resistance through hepatocyte-specific deletion of Jak2 in JAK2L and JAK2LA mice essentially eliminated detectable circulating IGF1 (Figure 1A). This abolished IGF1mediated negative feedback on central GH production and resulted in $\sim 200$ times higher fasting serum GH levels in both JAK2L and JAK2LA animals compared to the CON cohort (Figure 1B). Blood glucose levels varied little between the three genotypes, with only JAK2LA mice having statistically lower levels of fed glucose compared to CON mice (Figure 1C). CON mice appropriately showed lower serum insulin levels following on overnight fast, however JAK2L animals had both fed and fasting hyperinsulinemia (Figure 1D). This led to a large increase in HOMA-IR in the JAK2L mice that was normalized in JAK2LA animals (Figure 1E). Insulin tolerance testing (ITT) revealed augmented responsiveness in JAK2LA mice as compared to CON and JAK2L cohorts (Figure 1F). While HOMA-IR and ITT results were not concordant in these cohorts, HOMA-IR is more closely correlated with hepatic than peripheral insulin sensitivity (28), consistent with our previous published work using hyperinsulinemic-euglycemic clamps in JAK2L mice (20). Therefore, aged mice lacking hepatocyte Jak2 are GH resistant and develop insulin resistance in an adipocyte Jak2-dependent manner. 
JAK2L mice are lipodystrophic and have defective adipose tissue signaling in response to feeding. Aged JAK2L mice weighed less than the CON and JAK2LA cohorts in both the fed and fasted states (Figure 2A). Interestingly, JAK2L mice lost more weight following an overnight fast, consistent with the role of $\mathrm{GH}$ as a catabolic 'starvation' hormone (Figure 2B). Dual-energy absorptiometry (DEXA) scanning revealed an increase in lean mass and loss of fat mass in JAK2L mice that was normalized in the JAK2LA cohort (Figure 2C). While relative visceral (epididymal pads) fat mass did not statistically differ between the groups (Figure 2D), a large reduction in subcutaneous (inguinal pads) fat was observed in JAK2L animals, while JAK2LA mice had increased relative subcutaneous fat mass (Figure 2E). Histological sectioning revealed smaller adipocytes and sclerotic tissue in JAK2L inguinal fat pads (Figure 2F). In contrast, JAK2LA fat pads were histologically devoid of fibrotic lesions and contained adipocytes of a size comparable to $\mathrm{CON}$ (Figure $2 \mathrm{~F}$ ). At the molecular level, acute re-feeding induced mTORC1 activity, a major regulator of the fasting-fed transition (29), in inguinal adipose tissue (Figure $2 \mathrm{G}$ ). The adipose $\mathrm{mTORC1}$ response to re-feeding was entirely abolished in JAK2L but not JAK2LA mice (Figure 2G). Collectively, high levels of circulating GH in JAK2L mice is associated with lipodystrophy and aberrant fasting-fed transitional adipose tissue signaling that is governed by adipocyte JAK2.

Loss of hepatocyte Jak2 promotes increased hepatic lipid burden and dyslipidemia in an adipocyte Jak2-dependent manner. Given the association of IR and lipodystrophy with hepatosteatosis, we examined the livers of aged CON, JAK2L, and JAK2LA mice. As a percent of total body weight, JAK2L animals had increased liver weight compared to both 
the CON and JAK2LA cohorts (Figure 3A). In contrast, JAK2LA mice had decreased liver weight (Figure 3A). Both total hepatic triglycerides (Figure 3B) and cholesterol (Figure 3C) were increased in JAK2L mice in an adipocyte Jak2-dependent manner. Markers of liver injury, including ALT (Figure 3D), AST (Figure 3E), and AP (Figure 3F) were increased in JAK2KL animals, and only AST levels were not entirely normalized in the JAK2LA cohort. Neither fasting serum NEFA (Figure 3G) nor triglycerides (Figure 3H) differed between the groups. However, fasting total cholesterol (Figure 3I) as well as HDL-C (Figure 3J) and LDL-C (Figure 3K) levels were increased in JAK2L mice. Again, these levels were corrected by concomitant deletion of adipocyte Jak2. Thus, hepatic $\mathrm{GH}$ resistance promotes increased liver lipid burden, liver injury, and dyslipidemia via effects on adipocytes.

JAK2L mice spontaneously develop age-associated NAFLD and NASH in an adipocyte Jak2-dependent manner. Livers collected from the aged cohorts were sent to a pathologist for a blinded histological assessment. H\&E stained liver sections of aged CON mice demonstrated moderate lipid accumulation, which was slightly increased by hepatocyte-specific deletion of Jak2 (Figure 4A, B and C). In contrast, few lipid droplets were observed in mice with loss of both hepatocyte and adipocyte Jak2. Trichrome staining revealed some collagen deposition in the CON cohort, while fibrosis was more widespread in liver sections from JAK2L animals (Figure 4B). Similar to lipid droplets, Trichrome staining was reduced in JAK2LA mice. Upon quantification, $\sim 54 \%$ of CON hepatocytes had lipid droplets, as compared to $74 \%$ and $9 \%$ for the JAK2L and JAK2LA cohorts, respectively (Figure 4A and C). For CON and JAK2L livers, steatosis was 
primarily localized to zone 3, whereas in JAK2LA livers, lipid-laden hepatocytes were also found in the azonal and panacinar regions. Ballooning, an indication of cellular stress, was found to be rare in CON liver sections. In contrast, histological ballooning was much more common in centrizonal sections of JAK2L mice. The severity of ballooning was significantly reduced, but not entirely corrected, by concomitant deletion of adipocyte Jak2 (Figure 4D). Inflammatory lymphocytic foci were present in $\sim 2 / 3$ of sections examined from CON livers, while foci were identified in all JAK2L sections (Figure 4E). The number of inflammatory foci were reduced in JAK2LA sections as compared to JAK2L but were not completely normalized to CON levels. Scoring for fibrosis (Figure 4F) and Brunt (Figure 4G) staging resulted in highly significant increases for the JAK2L, but not JAK2LA, cohort as compared to CON mice. Thus, JAK2L mice develop NASH with aging with retained JAK2 functioning in adipocytes.

JAK2L mice spontaneously develop HCC. Given that a percentage of NASH patients develop HCC, we allowed cohorts of CON (N=17), JAK2L (N=24), and JAK2LA (N=20) mice to age until natural death (here, defined as veterinarian-mandated euthanasia). Upon necropsy, livers from both CON and JAK2L were pale and large, while JAK2LA mice had smaller, red-colored livers (Figure 5A). We noticed that a number of livers from JAK2L mice had large growths (Figure 5B). Immuno-histochemical assessment of the tumors found them to be fibrotic (Figure 5C) and positive from both Glutamine Synthetase and Glypican-3 (Figure 5D), indicative of HCC (30). Tumor sections were negative for CK19 (Figure 5D), favoring a diagnosis of HCC over cholangiocarcinoma (31). Quantification of HCC incidence in our cohort (Figure 5E) revealed a statistical increase 
in JAK2L mice (Chi-square test, $p=0.0077$ ), with an average age of discovery of $\sim 704$ days. In contrast, HCC incidence in the JAK2LA cohort did not differ from control mice. In summary, mice with high levels of circulating GH due to hepatocyte-specific deletion of Jak2 spontaneously develop HCC with age. In contrast, high levels of GH in the setting of dual hepatocyte and adipocyte Jak2 deficiency appear protected against ageassociated HCC.

GH increases hepatic lipid burden through adipocyte Jak2. JAK2 is known to transduce signals from cytokines other than $\mathrm{GH}$. Therefore, the phenotypic changes in hepatic metabolism observed in JAK2L and JAK2LA mice may not be entirely due to loss of GH signaling. To more definitely address the role of $\mathrm{GH}$, we injected control (CON) and mice lacking adipocyte JAK2 (JAK2A) with vehicle or GH daily for seven consecutive days. We chose JAK2A over JAK2LA mice in order to specifically address the role of adipocyte JAK2, without any confounding effects of combinatorial hepatocyte deletion, in mediating metabolic changes following $\mathrm{GH}$ exposure. Livers were collected and subjected to an LCMS panel targeting 200 lipids. Heat maps derived from the top $99 \%$ of lipid species detected show that GH treatment grossly augmented hepatic TAG (Figure 6A) and DAG (Figure 6B; for raw lipidomics data and concentration waterfall plots see Supplemental Table 1 and Supplemental Figure 1, respectively) species in CON mice. One week of GH treatment increased total hepatic TAG (Figure 6C) and DAG (Figure 6D) by an average of $\sim 18 \%$ and $\sim 15 \%$, respectively, in CON but not JAK2A mice. Hepatic cholesterol ester (CE) species were less affected by GH treatment (Figure 6E). However, GH treatment in CON mice did produce statistically higher levels of total hepatic CE than JAK2A animals 
(Figure 6G). GH treatment did not differentially affect total hepatic ceramide (CER) when comparing CON and JAK2A cohorts (Figures $6 \mathrm{~F}$ and $6 \mathrm{H}$ ). Therefore, acute $\mathrm{GH}$ treatment increases hepatic lipid burden but does so via adipocyte signaling. 


\section{DISCUSSION}

The association between IR and type 2 diabetes (T2D) with hepatosteatosis is strong (32). However, it presents a number of physiological quandaries. Chief among them is why fatty liver develops in the setting of IR (33). The normal physiological roles of insulin action on the liver are to suppress hepatic glucose production (HGP) and to stimulate TAG synthesis. Thus, the prediction would be that patients with T2D would have hyperglycemia (from the inability of insulin to suppress HGP) concomitant with "normal" liver lipid levels (from the inability of insulin to induce TAG synthesis). Nevertheless, patients with T2D, while indeed exhibiting increased gluconeogenesis, also display increased rates of TAG synthesis, suggesting the latter pathway remains active while the former loses insulin responsiveness. This paradox has been termed "selective hepatic insulin resistance" and has been primarily attributed to branch points (i.e. one arm regulating HGP and a second mediating TAG synthesis) of insulin signaling within the liver itself $(10,11)$. TAG synthesis via hepatic DNL has been proposed as the potential driver of fatty liver disease (34) and a target of hepatic GH action (25). The natural conclusion would be to treat T2D and metabolic liver disease by targeting liver intrinsic mechanisms.

An alternative hypothesis is that substrate delivery can drive HGP and TAG synthesis independent of direct effects of insulin on the liver (35). From this vantage, diseases associated with hepatic IR could be treated by either shutting off the supply of substrate or inhibiting substrate uptake. In support of this, a study on NAFLD patients demonstrated that the majority of hepatic TAG arises from NEFA, more than twice of that derived from 
DNL (36). Furthermore, it was reported in high fat diet-fed rats that NEFA but not hepatic TAG accumulation is the cause of liver cell injury (37). Regardless, registered interventional NASH trials almost exclusively examine the effects of agents targeting mechanisms within the liver. Therefore, the effects of abrogating substrate supply or uptake remain unexamined, although preclinical models are supportive of pursuing this paradigm $(37,38)$. Here, we show that inhibition of adipocyte JAK2 signaling prevents the sequelae of events associated with high levels of circulating $\mathrm{GH}$, beginning with insulin resistance and progressing through HCC. Specifically, the potential, if any, of inhibiting adipocyte $\mathrm{GH}$ signaling for the treatment of established NAFLD, NASH, and HCC are unknown.

Short term starvation is a natural state of IR and fatty liver (39). During nutrient deprivation, $\mathrm{GH}$ induces IR and promotes a lipolytic response (15). It has been hypothesized that $\mathrm{GH}$ resistance, which results from high circulating $\mathrm{GH}$ levels, is an adaptive response to states of under-nutrition to maintain euglycemia (40). Adipocyte (41) but not hepatocyte (42) IR results in LD and can promote fatty liver. This suggests that starvation and LD-induced fatty liver may share a common mechanism involving GHmediated adipocyte IR. Interestingly, while AN is characterized by GH resistance (i.e. elevated circulating $\mathrm{GH}$ in the face of low plasma IGF1), treatment of AN patients with $\mathrm{GH}$ further induces fat loss. This suggests that AN is actually a state of hepatic $\mathrm{GH}$ resistance while adipose tissue of AN patients remains $\mathrm{GH}$-responsive. Consistent with this, we now show that mice with elevated GH (JAK2L) lose more body weight following a 16-hour fast and are lipodystrophic. We interpret this as an unrestrained chronic state 
of adipose tissue insulin resistance and a condition mimicking metabolic starvation. At the molecular level, adipose tissue of JAK2L mice fail to induce mTORC1 following acute re-feeding, suggesting that $\mathrm{GH}$ impinges on mTORC1 activity. Interestingly, loss of mTORC1 specifically in adipocytes induces IR, fatty liver disease, and LD (43), a phenocopy of the JAK2L mice. These phenotypes associated with loss of hepatocyte Jak2 - IR, adipose tissue mTORC1 activation, LD, and fatty liver - are rescued in JAK2LA mice. Therefore, adipocytes govern GH-mediated catabolism and fat mobilization and subsequent perturbation of liver metabolism.

Adult GH deficiency (AGHD) commonly results in the development of NAFLD and NASH (24). The association of AGHD with fatty liver has been attributed to the ability of GH to inhibit hepatic de novo lipogenesis (DNL); hence, in the absence of liver GH action, DNL would be increased (25). This is in contrast to our previous work using in vivo ${ }^{2} \mathrm{H}_{2} \mathrm{O}$ labeling, as we found no increase in DNL in mice with fatty liver lacking hepatic $\mathrm{GH}$ signaling (26). Instead, using precise tissue-specific genetic models, we have determined that fatty acid uptake, via $\mathrm{Cd} 36$, is responsible for liver intrinsic mechanisms driving fatty liver in mice with disrupted hepatic GH signaling (38). Further, hepatosteatosis following hepatic $\mathrm{GH}$ resistance is dependent upon circulating $\mathrm{GH}$, and since $\mathrm{GH}$ cannot transduce hepatic signals in the setting of hepatic $\mathrm{GH}$ resistance, a tissue other than liver must mediate fatty liver development (26). Here, our lipidomics data demonstrate that oneweek of $\mathrm{GH}$ treatment promotes lipid deposition in livers of mice with intact hepatic $\mathrm{GH}$ signaling but not in mice lacking adipocyte $\mathrm{GH}$ signaling. Thus, both loss of hepatic $\mathrm{GH}$ sensitivity as well as continued hepatic exposure to $\mathrm{GH}$ in $\mathrm{GH}$-sensitive animals promotes 
fatty liver. This may seem contradictory but that hepatic $\mathrm{GH}$ resistance results in high levels of circulating $\mathrm{GH}$, similar to peripheral administration of recombinant $\mathrm{GH}$. As we show here, hepatosteatosis induced by either $\mathrm{GH}$ resistance or $\mathrm{GH}$ treatment is governed by adipocyte JAK2. Regardless, the association of AGHD with liver fat and dysfunction has led to the dominant paradigm of augmenting GH levels to treat NAFLD and NASH. We propose that this approach will likely worsen the pathophysiology of established NAFLD and NASH, as was reported for patients with anorexia nervosa (18) and HIVassociated LD $(44,45)$.

Cordoba-Chacon et al. recently reported that knockdown of hepatocyte Ghr in adult mice (aHepGHRkd) promotes fatty liver and NASH via increased DNL without severe alterations in systemic metabolism or adipose tissue lipolysis (46). This led them to conclude that liver disease from loss of hepatocyte $\mathrm{GH}$ signaling occurs via liver autonomous means. However, it is difficult to make these conclusions in the face of high circulating $\mathrm{GH}$, as reported in their aHepGHRkd mice, which can act on non-liver tissue, as well as insulin resistance (hyperinsulinemia and hyperglycemia). Previously, we controlled for augmented circulating $\mathrm{GH}$ in mice lacking hepatocyte $\mathrm{GH}$ signaling by global disruption of $\mathrm{GH}$ secretion (26). These studies demonstrated that circulating $\mathrm{GH}$ mediated onset of fatty liver in JAK2L mice, demonstrating that cells other than hepatocytes were responsible for development of hepatosteatosis. aHepGHRkd did not display increased plasma NEFA, which is consistent with our study here, as we did not observe a correlation between circulating fasting NEFA levels and liver pathology. However, given that circulating NEFA levels are the net result of release and uptake, and 
that loss of hepatic GH signaling induces Cd36 (which increases NEFA uptake), it is difficult to make any conclusions on the state of lipolysis. To directly address this, Cordoba-Chacon et al. used adipose explant cultures to demonstrate that aHepGHRkd had normal basal and stimulated rate of lipolysis. This is also consistent with our previously published results showing that $\mathrm{GH}$ does not affect basal lipolysis but instead specifically interferes with the ability of insulin to suppress lipolysis (19). Thus, without directly attending to high circulating $\mathrm{GH}$ levels present in aHepGHRkd mice via concomitant loss of adipocyte Ghr or global Gh disruption it is premature to conclude that fatty liver and NASH resulting from loss of hepatocyte Ghr occurs via liver autonomous means.

The role of JAK2/STAT5 signaling in HCC is well documented. Liver-specific Stat5 knockouts (STAT5L), like our JAK2L mice here, succumb to HCC upon aging without carcinogen or dietary intervention (47). In a study by Yu et al., STAT5L mice developed HCC at age 17 months, although it was a small cohort of four mice. In addition, a previous study examined liver tumorigenesis in JAK2L mice and reported a 68\% incidence at 60 weeks of age, although it is unclear if the tumors were HCC (48). Here, we report that 10/24 ( $42 \%)$ of JAK2L mice develop HCC with an average age of discovery of 704 days. Contrary to these findings, one report found that loss of hepatocyte JAK2 protects against liver tumorigenesis (49). However, the work by Shi et al. used chemical and dietary perturbations to induce liver disease and carcinogenesis. We propose that the reports, including our own, on aging-related $\mathrm{HCC}$ are mediated by adipocyte $\mathrm{GH}$ signaling and governed by IR while orally-administered carcinogens and dietary models directly affect 
hepatocytes. Our work here demonstrates that JAK2L mice succumb specifically to the sequalae of events leading to metabolic liver disease and, while it is experimentally cumbersome to wait $\sim 2$ years for HCC development, may provide a more faithful model of human IR-associated HCC.

Acromegaly predisposes to cancer, and cancer has become a leading cause of acromegaly-associated deaths, despite an overall increase in life expectancy due to new treatments (50). The most parsimonious rationale for the mechanism of cancer onset due to high levels of $\mathrm{GH}$ is reduced plasma IGF1. However, we report here that mice with hepatic $\mathrm{GH}$ resistance indeed succumb to $\mathrm{HCC}$, despite undetectable circulating IGF1. Further, while treatment of Laron Syndrome (LS) patients (loss of GH signaling) with recombinant IGF1 does normalize linear growth rates, restoration of IGF1 levels by pharmacological means does not prevent the immunity from cancer appreciated in those with LS (51). Collectively then, we propose that GH predisposes to cancer via its role in metabolism and not IGF1 production, possibly through actions on adipose tissue. Adipose tissue dysfunction, and IR in particular, is highly associated with cancer and adipocytes have been proposed as mediators of tumor cell behavior (52). How insulin resistant adipocytes promote oncogenesis is unknown, but a role for fatty acid receptors has been proposed (53). In addition, metabolic re-programming in HCC is mediated by the master oncogene Myc (54) and MYC levels themselves are induced by cellular exposure to fatty acids (55). Interestingly, a single bolus of GH increased hepatic Myc expression within one hour of administration (56). Therefore, it is tempting to speculate that adipocytes release a factor in a JAK2-dependent manner that subsequently induces 
hepatic Myc, leading to a favorable metabolic environment for development of HCC. Given that HCCs are 'addicted' to sustained MYC expression (57), it will be interesting to test if inhibition of adipocyte JAK2 will lead to regression of established HCC, what would ultimately be akin to a kind of 'metabolite addiction'. 


\section{METHODS}

Study Approval. All procedures performed on animals were in accordance with regulations and established guidelines and were reviewed and approved by the Institutional Animal Care and Use Committee at the University of California, San Francisco.

Animals and diets. The generation of JAK2L and JAK2LA mice employing Albumin:CRE and Adiponectin:CRE was previously described (20). For our studies reported here, Jak2 $2^{\text {lox/lox }}(58)$ were used as controls and backcrossed onto the C57BL/6 background for at least nine generations. All mice in these studies were fed PicoLab Mouse Diet 20 (Lab Diet \#5058; percent calories provided by protein $23 \%$, fat $22 \%$, carbohydrate $55 \%$ ) throughout their lifetime.

Study designs. Mice were aged until 70-75 weeks for metabolic studies. Blood was collected by retro-orbital puncture at 17:00 prior to food removal as the fed state. The following morning at 09:00 mice were sacrificed and blood and tissues collected as the fasted state. For re-feeding studies, mice fasted overnight were sacrificed or re-fed for 30 minutes prior to tissue collection by placing a pellet of food into the cages. Tissues were flash frozen on liquid nitrogen for Western blot, lipidomic, and transcriptomic analyses. Tissues were fixed with $10 \%$ neutral-buffered formalin for 24 hours for histological analyses. Blood glucose and serum insulin levels were determined by glucometer readings (Bayer Contour) and ELISA (Alpco), respectively. Serum IGF-1 
(R\&D MG100) and GH (Millipore EZRMGH-45K) levels were determined by ELISA. For insulin tolerance testing, mice were fasted for four hours (09:00-13:00) followed by intraperitoneal injection of 2 U/kg insulin (Novolin® Novo Nordisk, Bagsvaerd Denmark). Blood glucose levels were determined by tail prick using a hand-held glucometer at the times indicated. HOMA-IR was calculated as a ratio of fasting blood glucose (mg/dL):fasting serum insulin (mU/L) divided by 405 (59). Total fat mass was determined by Dual-energy X-ray absorptiometry. All clinical chemistry was done on terminallycollected serum from 16-hour fasted mice and done at the University of California, Davis Comparative Pathology Lab Core. For acute GH studies, CON and JAK2A mice were injected (i.p.) with vehicle (0.03 M NaHCO3, $0.15 \mathrm{M} \mathrm{NaCl}, \mathrm{pH} 9.5)$ or $5 \mathrm{mg} / \mathrm{kg}$ recombinant mouse GH (Dr. A. F. Parlow, National Hormone and Peptide Program, UCLA, Torrance, CA USA) daily at 09:00 for 7 days and sacrificed 4 hours after a fast and the final injection.

Hepatic TAG and cholesterol measurements and Western blots. Bits of frozen inguinal adipose pads were weighed and re-suspended in $1 \mathrm{X}$ cell lysis buffer (Cell Signaling Technology 9803) with protease (Roche 4693132001) and phosphatase (Roche 4906845001) inhibitor cocktail at a final volume of $50 \mathrm{mg} / \mathrm{ml}$ and homogenized using the OmniTH homogenizer. 20 ul of lysates were used to determine cholesterol (Wako 999-02601) and triglyceride (Infinity reagent, Thermo TR22421) levels. Alternatively, lysates were ran out on $4-12 \%$ gradient gels and probed with antiphospho(T389) p70S6K (Cell Signaling 9205) and anti-p70S6K (Cell Signaling 2708) antibodies. Western blots were developed with SuperSignal West Femto reagent (Thermo 34095) and developed using a ChemiDoc Imaging System (Bio-Rad). 
Liver histology and pathological analyses. Tissues were collected and fixed in $10 \%$ neutral-buffered formalin for 24 hours. Subsequently, tissues were washed and stored in $70 \%$ ethanol until embedding and sectioning. Sectioning and staining were carried out by the UCSF Liver Center core. H\&E, Trichrome, reticulin, and immunohistochemical stains were reviewed and evaluated by a blinded GI/Liver pathologist. Livers were evaluated and scored according to methods by Kleiner and Brunt (60). Liver tumors were evaluated by H\&E, Trichrome, and reticulin patterns and further evaluated by immunohistochemical staining for CK19, Glutamine Synthetase, and Glypican 3. Immunohistochemical staining was performed by the UCSF Liver Center core.

Lipidomics. Lipidomics were done exactly as described (20).

Statisitcs and graphics. All statistical tests and figures were done using GraphPad Prism v8.0.

\section{Acknowledgements}

This study was supported by National Institutes of Health (NIH) Grants 1R01DK091276 (to E.J.W.) and DK076169 (E.J.W.), We also gratefully acknowledge the support of the James Peter Read Foundation, the University of California, San Francisco (UCSF) Cardiovascular Research Institute, the UCSF Diabetes Center (P30 DK063720), and the UCSF Liver Center (P30 
DK026743). We would like to thank Dr. Kay-Uwe Wagner from the University of Nebraska for kindly providing the Jak2 conditional mice.

\section{Author contributions}

J. L. T. and K. C. C. carried out experiments for Figures 1-5. J. L. T. and C. G. W. did the ITTs for Figure 1. J. L. T. and D. L. performed experiments for Figure 6. A. N. M. did all liver pathological analyses. N. B. V. and M. C. performed lipidomics, made heat map and waterfall plots, and provided Supplemental Table 1. K. C. C. carried out all ELISAs and Western blots. K. C. C. and E. J. W. conceived of the experiments, made the figures, performed statistical analyses, and wrote the paper. 


\section{REFERENCES}

1. Younossi Z, Anstee QM, Marietti M, Hardy T, Henry L, Eslam M, George J, Bugianesi E. Global burden of NAFLD and NASH: trends, predictions, risk factors and prevention. Nat Rev Gastroenterol Hepatol. 2018;15(1):11-20. Epub 2017/09/21. doi: 10.1038/nrgastro.2017.109. PubMed PMID: 28930295.

2. Kanwal F, Kramer JR, Mapakshi S, Natarajan Y, Chayanupatkul M, Richardson PA, Li L, Desiderio R, Thrift AP, Asch SM, Chu J, El-Serag HB. Risk of Hepatocellular Cancer in Patients with Non-alcoholic Fatty Liver Disease. Gastroenterology. 2018. Epub 2018/08/26. doi: 10.1053/j.gastro.2018.08.024. PubMed PMID: 30144434.

3. Ghouri YA, Mian I, Rowe JH. Review of hepatocellular carcinoma: Epidemiology, etiology, and carcinogenesis. J Carcinog. 2017;16:1. Epub 2017/07/12. doi: 10.4103/jcar.JCar_9_16. PubMed PMID: 28694740; PMCID: PMC5490340.

4. Hansen HH, Feigh M, Veidal SS, Rigbolt KT, Vrang N, Fosgerau K. Mouse models of nonalcoholic steatohepatitis in preclinical drug development. Drug Discov Today. 2017;22(11):1707-18. Epub 2017/07/09. doi: 10.1016/j.drudis.2017.06.007. PubMed PMID: 28687459.

5. Van Herck MA, Vonghia L, Francque SM. Animal Models of Nonalcoholic Fatty Liver Disease-A Starter's Guide. Nutrients. 2017;9(10). Epub 2017/09/28. doi: 10.3390/nu9101072. PubMed PMID: 28953222; PMCID: PMC5691689.

6. Marchesini G, Brizi M, Morselli-Labate AM, Bianchi G, Bugianesi E, McCullough AJ, Forlani G, Melchionda N. Association of nonalcoholic fatty liver disease with insulin resistance. Am J Med. 1999;107(5):450-5. Epub 1999/11/24. PubMed PMID: 10569299. 
7. Marchesini G, Brizi M, Bianchi G, Tomassetti S, Bugianesi E, Lenzi M, McCullough AJ, Natale S, Forlani G, Melchionda N. Nonalcoholic fatty liver disease: a feature of the metabolic syndrome. Diabetes. 2001;50(8):1844-50. Epub 2001/07/27. PubMed PMID: 11473047.

8. Mancina RM, Matikainen N, Maglio C, Soderlund S, Lundbom N, Hakkarainen A, Rametta R, Mozzi E, Fargion S, Valenti L, Romeo S, Taskinen MR, Boren J. Paradoxical dissociation between hepatic fat content and de novo lipogenesis due to PNPLA3 sequence variant. J Clin Endocrinol Metab. 2015;100(5):E821-5. Epub 2015/03/13. doi: 10.1210/jc.2014-4464. PubMed PMID: 25763607.

9. Geisler CE, Renquist BJ. Hepatic lipid accumulation: cause and consequence of dysregulated glucoregulatory hormones. J Endocrinol. 2017;234(1):R1-R21. doi: 10.1530/JOE-16-0513. PubMed PMID: 28428362.

10. Brown MS, Goldstein JL. Selective versus total insulin resistance: a pathogenic paradox. Cell Metab. 2008;7(2):95-6. Epub 2008/02/06. doi: 10.1016/j.cmet.2007.12.009. PubMed PMID: 18249166.

11. Ferris HA, Kahn CR. Unraveling the Paradox of Selective Insulin Resistance in the Liver: the Brain-Liver Connection. Diabetes. 2016;65(6):1481-3. Epub 2016/05/26. doi: 10.2337/dbi16-0010. PubMed PMID: 27222392; PMCID: PMC4878421.

12. Moller L, Stodkilde-Jorgensen H, Jensen FT, Jorgensen JO. Fasting in healthy subjects is associated with intrahepatic accumulation of lipids as assessed by $1 \mathrm{H}$ magnetic resonance spectroscopy. Clin Sci (Lond). 2008;114(8):547-52. Epub 2007/11/10. doi: 10.1042/CS20070217. PubMed PMID: 17990983. 
13. Melvin A, O'Rahilly S, Savage DB. Genetic syndromes of severe insulin resistance. Curr Opin Genet Dev. 2018;50:60-7. Epub 2018/02/27. doi: 10.1016/j.gde.2018.02.002. PubMed PMID: 29477938.

14. Duval C, Thissen U, Keshtkar S, Accart B, Stienstra R, Boekschoten MV, Roskams T, Kersten S, Muller M. Adipose tissue dysfunction signals progression of hepatic steatosis towards nonalcoholic steatohepatitis in C57BL/6 mice. Diabetes. 2010;59(12):3181-91. Epub 2010/09/23. doi: 10.2337/db10-0224. PubMed PMID: 20858684; PMCID: PMC2992781.

15. Sakharova AA, Horowitz JF, Surya S, Goldenberg N, Harber MP, Symons K, Barkan A. Role of growth hormone in regulating lipolysis, proteolysis, and hepatic glucose production during fasting. J Clin Endocrinol Metab. 2008;93(7):2755-9. Epub 2008/04/17. doi: 10.1210/jc.2008-0079. PubMed PMID: 18413425; PMCID: PMC2453052.

16. Gahete MD, Cordoba-Chacon J, Luque RM, Kineman RD. The rise in growth hormone during starvation does not serve to maintain glucose levels or lean mass but is required for appropriate adipose tissue response in female mice. Endocrinology. 2013;154(1):263-9. Epub 2012/11/15. doi: 10.1210/en.2012-1849. PubMed PMID: 23150490; PMCID: PMC3529368.

17. Tzagournis M, George J, Herrold J. Increased growth hormone in partial and total lipoatrophy. Diabetes. 1973;22(5):388-96. Epub 1973/05/01. PubMed PMID: 4700052.

18. Fazeli PK, Lawson EA, Prabhakaran R, Miller KK, Donoho DA, Clemmons DR, Herzog DB, Misra M, Klibanski A. Effects of recombinant human growth hormone in anorexia nervosa: a randomized, placebo-controlled study. J Clin Endocrinol Metab. 
2010;95(11):4889-97. doi: 10.1210/jc.2010-0493. PubMed PMID: 20668047; PMCID: 2968733.

19. Corbit KC, Camporez JP, Tran JL, Wilson CG, Lowe DA, Nordstrom SM, Ganeshan K, Perry RJ, Shulman GI, Jurczak MJ, Weiss EJ. Adipocyte JAK2 mediates growth hormone-induced hepatic insulin resistance. JCI Insight. 2017;2(3):e91001. doi: 10.1172/jci.insight.91001. PubMed PMID: 28194444; PMCID: PMC5291741.

20. Corbit KC, Camporez JPG, Edmunds LR, Tran JL, Vera NB, Erion DM, Deo RC, Perry RJ, Shulman GI, Jurczak MJ, Weiss EJ. Adipocyte JAK2 Regulates Hepatic Insulin Sensitivity Independently of Body Composition, Liver Lipid Content, and Hepatic Insulin Signaling. Diabetes. 2018;67(2):208-21. Epub 2017/12/06. doi: 10.2337/db17-0524. PubMed PMID: 29203511.

21. Guevara-Aguirre J, Balasubramanian P, Guevara-Aguirre M, Wei M, Madia F, Cheng CW, Hwang D, Martin-Montalvo A, Saavedra J, Ingles S, de Cabo R, Cohen P, Longo VD. Growth hormone receptor deficiency is associated with a major reduction in pro-aging signaling, cancer, and diabetes in humans. Sci Transl Med. 2011;3(70):70ra13. doi: 10.1126/scitranslmed.3001845. PubMed PMID: 21325617; PMCID: 3357623.

22. Guevara-Aguirre J, Procel P, Guevara C, Guevara-Aguirre M, Rosado V, Teran E. Despite higher body fat content, Ecuadorian subjects with Laron syndrome have less insulin resistance and lower incidence of diabetes than their relatives. Growth Horm IGF Res. 2016;28:76-8. doi: 10.1016/j.ghir.2015.08.002. PubMed PMID: 26259979.

23. Olarescu NC, Bollerslev J. The Impact of Adipose Tissue on Insulin Resistance in Acromegaly. Trends Endocrinol Metab. 2016;27(4):226-37. doi: 10.1016/j.tem.2016.02.005. PubMed PMID: 26948712. 
24. Takahashi Y. The Role of Growth Hormone and Insulin-Like Growth Factor-I in the Liver. Int J Mol Sci. 2017;18(7). Epub 2017/07/06. doi: 10.3390/ijms18071447. PubMed PMID: 28678199; PMCID: PMC5535938.

25. Cordoba-Chacon J, Majumdar N, List EO, Diaz-Ruiz A, Frank SJ, Manzano A, Bartrons R, Puchowicz M, Kopchick JJ, Kineman RD. Growth Hormone Inhibits Hepatic De Novo Lipogenesis in Adult Mice. Diabetes. 2015;64(9):3093-103. doi: 10.2337/db150370. PubMed PMID: 26015548; PMCID: 4542445.

26. Sos BC, Harris C, Nordstrom SM, Tran JL, Balazs M, Caplazi P, Febbraio M, Applegate MA, Wagner KU, Weiss EJ. Abrogation of growth hormone secretion rescues fatty liver in mice with hepatocyte-specific deletion of JAK2. J Clin Invest. 2011;121(4):1412-23. doi: 10.1172/JCI42894. PubMed PMID: 21364286; PMCID: 3069761.

27. Nordstrom SM, Tran JL, Sos BC, Wagner KU, Weiss EJ. Disruption of JAK2 in adipocytes impairs lipolysis and improves fatty liver in mice with elevated $\mathrm{GH}$. Mol Endocrinol. 2013;27(8):1333-42. doi: 10.1210/me.2013-1110. PubMed PMID: 23782652; PMCID: 4188962.

28. Tripathy D, Almgren P, Tuomi T, Groop L. Contribution of insulin-stimulated glucose uptake and basal hepatic insulin sensitivity to surrogate measures of insulin sensitivity. Diabetes Care. 2004;27(9):2204-10. Epub 2004/08/31. PubMed PMID: 15333485.

29. Laplante M, Sabatini DM. mTOR signaling in growth control and disease. Cell. 2012;149(2):274-93. Epub 2012/04/17. doi: 10.1016/j.cell.2012.03.017. PubMed PMID: 22500797; PMCID: PMC3331679. 
30. Wasfy RE, Shams Eldeen AA. Roles of Combined Glypican-3 and Glutamine Synthetase in Differential Diagnosis of Hepatocellular Lesions. Asian Pac J Cancer Prev. 2015;16(11):4769-75. Epub 2015/06/25. PubMed PMID: 26107238.

31. Tao LY, Cai L, He XD, Liu W, Qu Q. Comparison of serum tumor markers for intrahepatic cholangiocarcinoma and hepatocellular carcinoma. Am Surg. 2010;76(11):1210-3. Epub 2010/12/15. PubMed PMID: 21140686.

32. Gaggini M, Morelli M, Buzzigoli E, DeFronzo RA, Bugianesi E, Gastaldelli A. Nonalcoholic fatty liver disease (NAFLD) and its connection with insulin resistance, dyslipidemia, atherosclerosis and coronary heart disease. Nutrients. 2013;5(5):1544-60. Epub 2013/05/15. doi: 10.3390/nu5051544. PubMed PMID: 23666091; PMCID: PMC3708335.

33. Brown MS, Goldstein JL. Selective versus Total Insulin Resistance: A Pathogenic Paradox. Cell Metabolism. 2008;7(2):95-6. doi: 10.1016/j.cmet.2007.12.009.

34. Lally JSV, Ghoshal S, DePeralta DK, Moaven O, Wei L, Masia R, Erstad DJ, Fujiwara N, Leong V, Houde VP, Anagnostopoulos AE, Wang A, Broadfield LA, Ford RJ, Foster RA, Bates J, Sun H, Wang T, Liu H, Ray AS, Saha AK, Greenwood J, Bhat S, Harriman G, Miao W, Rocnik JL, Westlin WF, Muti P, Tsakiridis T, Harwood HJ, Jr., Kapeller R, Hoshida Y, Tanabe KK, Steinberg GR, Fuchs BC. Inhibition of Acetyl-CoA Carboxylase by Phosphorylation or the Inhibitor ND-654 Suppresses Lipogenesis and Hepatocellular Carcinoma. Cell Metab. 2018. Epub 2018/09/25. doi: 10.1016/j.cmet.2018.08.020. PubMed PMID: 30244972.

35. Vatner DF, Majumdar SK, Kumashiro N, Petersen MC, Rahimi Y, Gattu AK, Bears M, Camporez JP, Cline GW, Jurczak MJ, Samuel VT, Shulman GI. Insulin-independent 
regulation of hepatic triglyceride synthesis by fatty acids. Proc Natl Acad Sci U S A. 2015;112(4):1143-8. Epub 2015/01/08. doi: 10.1073/pnas.1423952112. PubMed PMID: 25564660; PMCID: PMC4313795.

36. Donnelly $\mathrm{KL}$, Smith $\mathrm{Cl}$, Schwarzenberg SJ, Jessurun J, Boldt MD, Parks EJ. Sources of fatty acids stored in liver and secreted via lipoproteins in patients with nonalcoholic fatty liver disease. J Clin Invest. 2005;115(5):1343-51. Epub 2005/05/03. doi: 10.1172/JCI23621. PubMed PMID: 15864352; PMCID: PMC1087172.

37. Liu J, Han L, Zhu L, Yu Y. Free fatty acids, not triglycerides, are associated with non-alcoholic liver injury progression in high fat diet induced obese rats. Lipids Health Dis. 2016;15:27. doi: 10.1186/s12944-016-0194-7. PubMed PMID: 26868515; PMCID: 4750181.

38. Wilson CG, Tran JL, Erion DM, Vera NB, Febbraio M, Weiss EJ. HepatocyteSpecific Disruption of CD36 Attenuates Fatty Liver and Improves Insulin Sensitivity in HFD-Fed Mice. Endocrinology. 2016;157(2):570-85. doi: 10.1210/en.2015-1866. PubMed PMID: 26650570; PMCID: 4733118.

39. Lundbaek K. Metabolic abnormalities in starvation diabetes. Yale J Biol Med. 1948;20(6):533-44. Epub 1948/07/01. PubMed PMID: 18872320; PMCID: PMC2602371. 40. Fazeli PK, Klibanski A. Determinants of $\mathrm{GH}$ resistance in malnutrition. J Endocrinol. 2014;220(3):R57-65. Epub 2013/12/24. doi: 10.1530/JOE-13-0477. PubMed PMID: 24363451; PMCID: PMC3994591.

41. Qiang G, Whang Kong H, Xu S, Pham HA, Parlee SD, Burr AA, Gil V, Pang J, Hughes A, Gu X, Fantuzzi G, MacDougald OA, Liew CW. Lipodystrophy and severe metabolic dysfunction in mice with adipose tissue-specific insulin receptor ablation. Mol 
Metab. 2016;5(7):480-90. doi: 10.1016/j.molmet.2016.05.005. PubMed PMID: 27408774; PMCID: PMC4921803.

42. Michael MD, Kulkarni RN, Postic C, Previs SF, Shulman GI, Magnuson MA, Kahn CR. Loss of insulin signaling in hepatocytes leads to severe insulin resistance and progressive hepatic dysfunction. Mol Cell. 2000;6(1):87-97. Epub 2000/08/19. PubMed PMID: 10949030.

43. Lee PL, Tang Y, Li H, Guertin DA. Raptor/mTORC1 loss in adipocytes causes progressive lipodystrophy and fatty liver disease. Mol Metab. 2016;5(6):422-32. doi: 10.1016/j.molmet.2016.04.001. PubMed PMID: 27257602; PMCID: PMC4877665.

44. Lo J, You S, Canavan B, et al. Low-dose physiological growth hormone in patients with hiv and abdominal fat accumulation: A randomized controlled trial. JAMA. 2008;300(5):509-19. doi: 10.1001/jama.300.5.509.

45. Schwarz J-M, Mulligan K, Lee J, Lo JC, Wen M, Noor MA, Grunfeld C, Schambelan M. Effects of Recombinant Human Growth Hormone on Hepatic Lipid and Carbohydrate Metabolism in HIV-Infected Patients with Fat Accumulation. Journal of Clinical Endocrinology \& Metabolism. 2002;87(2):942. doi: 10.1210/jc.87.2.942.

46. Cordoba-Chacon J, Sarmento-Cabral A, Del Rio-Moreno M, Diaz-Ruiz A, Subbaiah PV, Kineman RD. Adult-Onset Hepatocyte GH Resistance Promotes NASH in Male Mice, Without Severe Systemic Metabolic Dysfunction. Endocrinology. 2018;159(11):3761-74. Epub 2018/10/09. doi: 10.1210/en.2018-00669. PubMed PMID: 30295789; PMCID: PMC6202859.

47. Yu JH, Zhu BM, Riedlinger G, Kang K, Hennighausen L. The liver-specific tumor suppressor STAT5 controls expression of the reactive oxygen species-generating 
enzyme NOX4 and the proapoptotic proteins PUMA and BIM in mice. Hepatology. 2012;56(6):2375-86. Epub 2012/06/20. doi: 10.1002/hep.25900. PubMed PMID: 22711600; PMCID: PMC3505809.

48. Themanns M, Mueller KM, Kessler SM, Golob-Schwarzl N, Mohr T, Kaltenecker D, Bourgeais J, Paier-Pourani J, Friedbichler K, Schneller D, Schlederer M, ZebedinBrandl E, Terracciano LM, Han X, Kenner L, Wagner KU, Mikulits W, Kozlov AV, Heim MH, Gouilleux F, Haybaeck J, Moriggl R. Hepatic Deletion of Janus Kinase 2 Counteracts Oxidative Stress in Mice. Sci Rep. 2016;6:34719. Epub 2016/10/08. doi: 10.1038/srep34719. PubMed PMID: 27713471; PMCID: PMC5054456.

49. Shi SY, Luk CT, Schroer SA, Kim MJ, Dodington DW, Sivasubramaniyam T, Lin L, Cai EP, Lu SY, Wagner KU, Bazinet RP, Woo M. Janus Kinase 2 (JAK2) Dissociates Hepatosteatosis from Hepatocellular Carcinoma in Mice. J Biol Chem. 2017;292(9):378999. Epub 2017/01/20. doi: 10.1074/jbc.M116.752519. PubMed PMID: 28100771; PMCID: PMC5339761.

50. Bolfi F, Neves AF, Boguszewski CL, Nunes-Nogueira VS. Mortality in acromegaly decreased in the last decade: a systematic review and meta-analysis. Eur J Endocrinol. 2018;179(1):59-71. Epub 2018/05/17. doi: 10.1530/EJE-18-0255. PubMed PMID: 29764907.

51. Laron Z, Kauli R. Fifty seven years of follow-up of the Israeli cohort of Laron Syndrome patients-From discovery to treatment. Growth Horm IGF Res. 2016;28:53-6. Epub 2015/08/27. doi: 10.1016/j.ghir.2015.08.004. PubMed PMID: 26307357.

52. Duong MN, Geneste A, Fallone F, Li X, Dumontet C, Muller C. The fat and the bad: Mature adipocytes, key actors in tumor progression and resistance. Oncotarget. 
2017;8(34):57622-41. Epub 2017/09/17. doi: 10.18632/oncotarget.18038. PubMed PMID: 28915700; PMCID: PMC5593672.

53. Suckow AT, Briscoe CP. Key Questions for Translation of FFA Receptors: From Pharmacology to Medicines. Handb Exp Pharmacol. 2017;236:101-31. Epub 2016/11/23. doi: 10.1007/164_2016_45. PubMed PMID: 27873087.

54. Camarda R, Williams J, Goga A. In vivo Reprogramming of Cancer Metabolism by MYC. Front Cell Dev Biol. 2017;5:35. Epub 2017/04/27. doi: 10.3389/fcell.2017.00035. PubMed PMID: 28443280; PMCID: PMC5386977.

55. Artwohl M, Lindenmair A, Sexl V, Maier C, Rainer G, Freudenthaler A, Huttary N, Wolzt M, Nowotny P, Luger A, Baumgartner-Parzer SM. Different mechanisms of saturated versus polyunsaturated FFA-induced apoptosis in human endothelial cells. J Lipid Res. 2008;49(12):2627-40. Epub 2008/08/07. doi: 10.1194/jlr.M800393-JLR200. PubMed PMID: 18682607.

56. Murphy LJ, Bell GI, Friesen HG. Growth hormone stimulates sequential induction of c-myc and insulin-like growth factor I expression in vivo. Endocrinology. 1987;120(5):1806-12. Epub 1987/05/01. doi: 10.1210/endo-120-5-1806. PubMed PMID: 3569112.

57. Shachaf CM, Kopelman AM, Arvanitis C, Karlsson A, Beer S, Mandl S, Bachmann MH, Borowsky AD, Ruebner B, Cardiff RD, Yang Q, Bishop JM, Contag CH, Felsher DW. MYC inactivation uncovers pluripotent differentiation and tumour dormancy in hepatocellular cancer. Nature. 2004;431(7012):1112-7. Epub 2004/10/12. doi: 10.1038/nature03043. PubMed PMID: 15475948. 
58. Krempler A, Qi Y, Triplett AA, Zhu J, Rui H, Wagner KU. Generation of a conditional knockout allele for the Janus kinase 2 (Jak2) gene in mice. Genesis. 2004;40(1):52-7. Epub 2004/09/09. doi: 10.1002/gene.20063. PubMed PMID: 15354294. 59. Yokoyama H, Emoto M, Fujiwara S, Motoyama K, Morioka T, Komatsu M, Tahara H, Shoji T, Okuno Y, Nishizawa Y. Quantitative insulin sensitivity check index and the reciprocal index of homeostasis model assessment in normal range weight and moderately obese type 2 diabetic patients. Diabetes Care. 2003;26(8):2426-32. Epub 2003/07/29. PubMed PMID: 12882874.

60. Kleiner DE, Brunt EM. Nonalcoholic fatty liver disease: pathologic patterns and biopsy evaluation in clinical research. Semin Liver Dis. 2012;32(1):3-13. Epub 2012/03/16. doi: 10.1055/s-0032-1306421. PubMed PMID: 22418883. 


\section{Figure 1}

A.

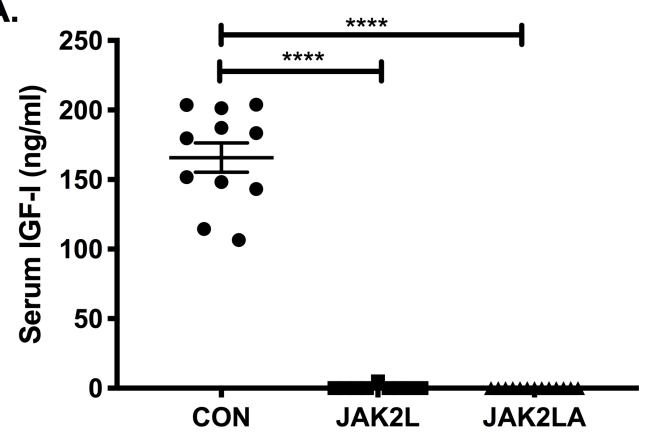

C.

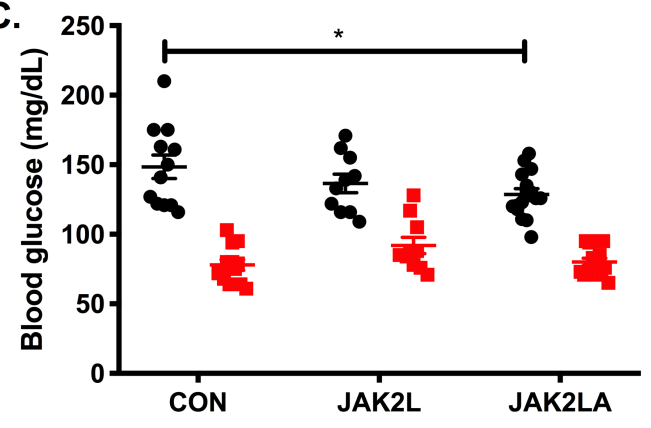

E.

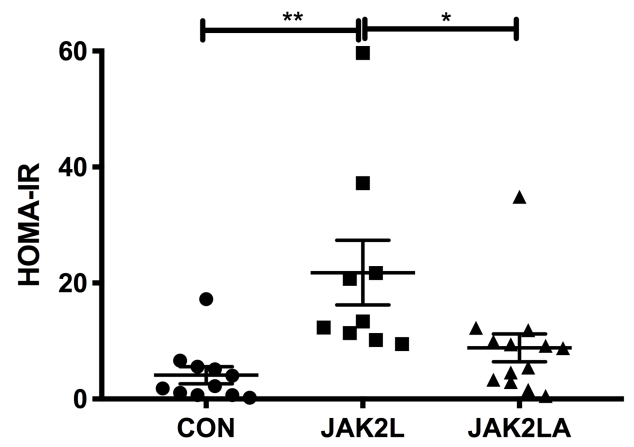

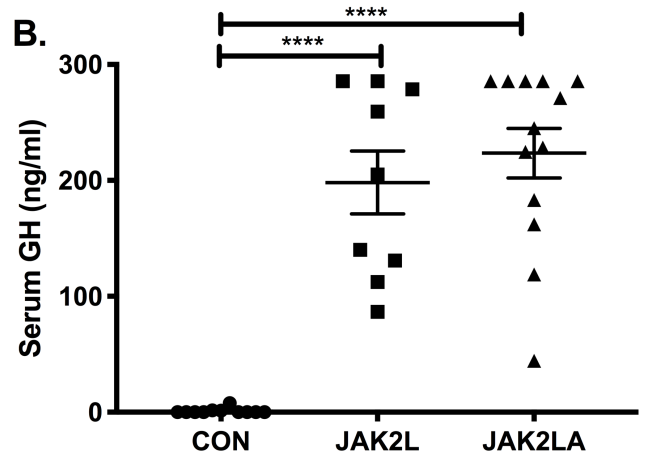

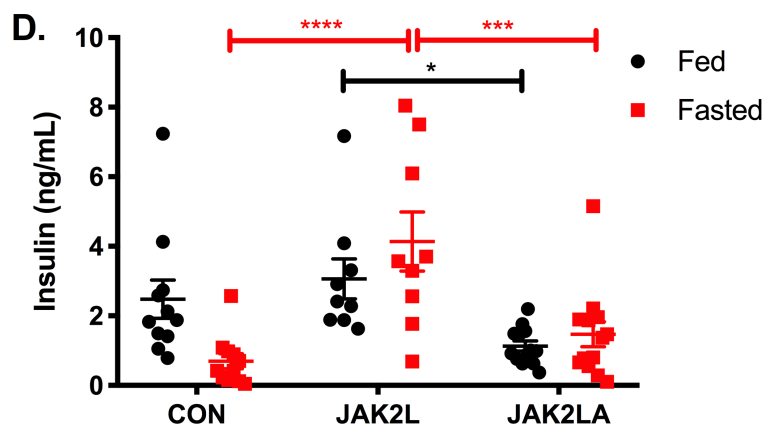

F.

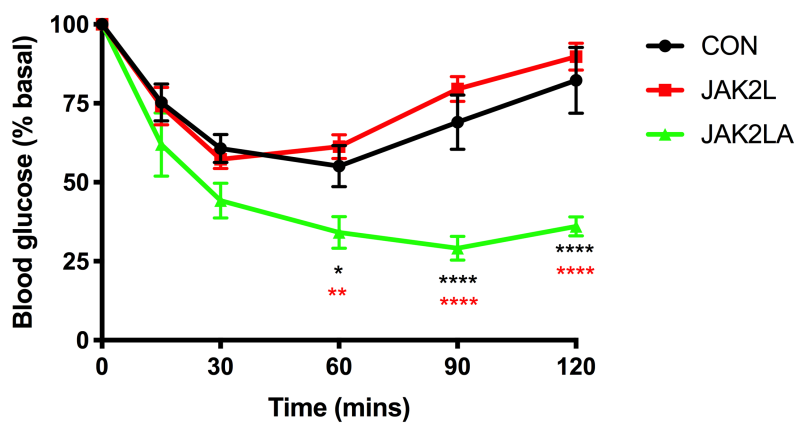

Figure 1: hepatic GH resistance does not correlate with insulin resistance in mice lacking adipocyte Jak2. Serum (A.) IGF-1 and (B.) GH levels in 16-hour fasted control (CON), JAK2L, and JAK2LA mice. (C.) Blood glucose and (D.) serum insulin levels in ad lib fed (black) and 16-hour fasted (red) mice. (E.) Homeostatic assessment model of insulin resistance (HOMA-IR) values. (F.) Insulin tolerance testing in control (CON, 
black), JAK2L (red), and JAK2LA (green) mice. N=9-13 (A, B, D, and E), 10-15 (C), and

6-8 (F). ${ }^{*} p<0.05,{ }^{* *} p<0.01,{ }^{* * *} p<0.001,{ }^{* * *} p<0.0001$ by 1 Way $(\mathrm{A}, \mathrm{B}$, and $\mathrm{E})$ and 2 Way $\operatorname{ANOVA}(C, D$, and $F)$. 
Figure 2

A.

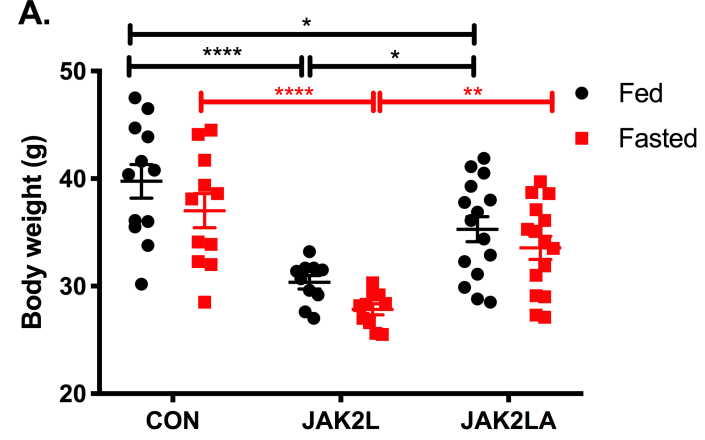

C.

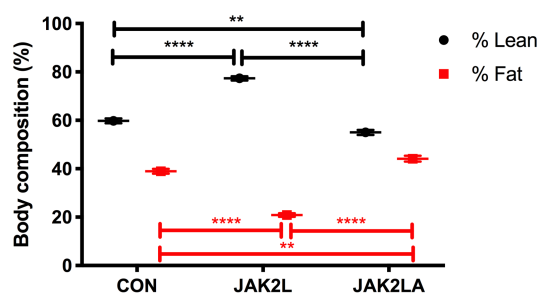

D.

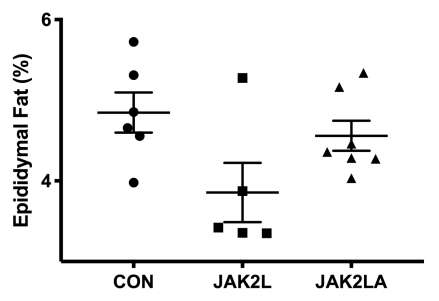

B.

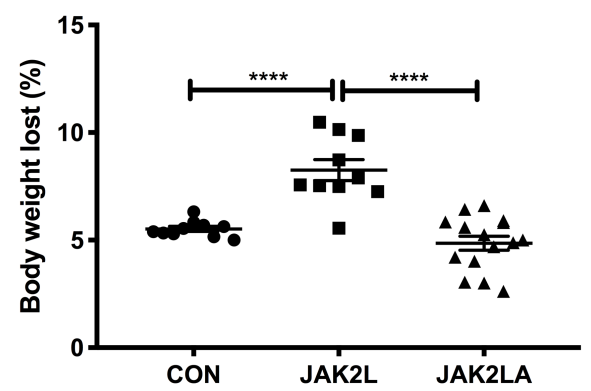

E.

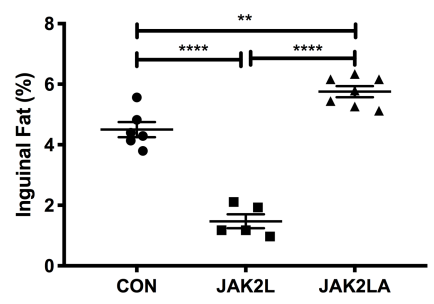

F.

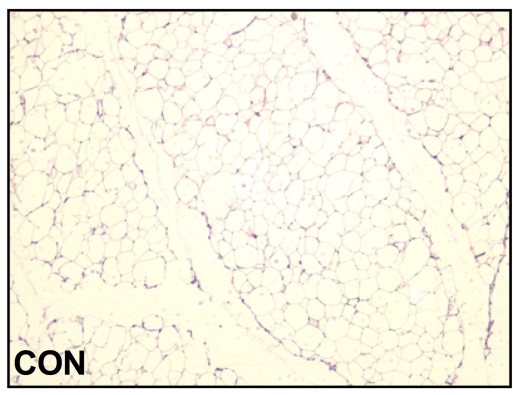

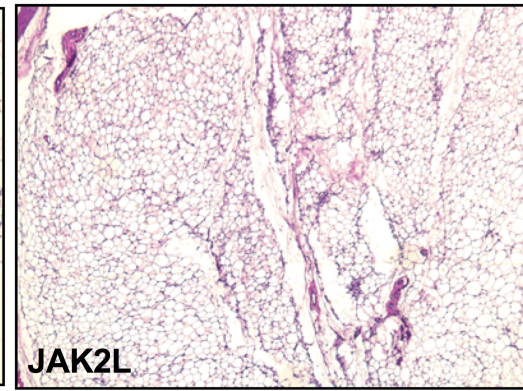

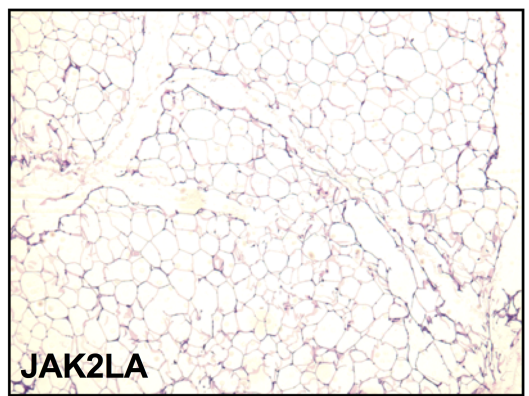

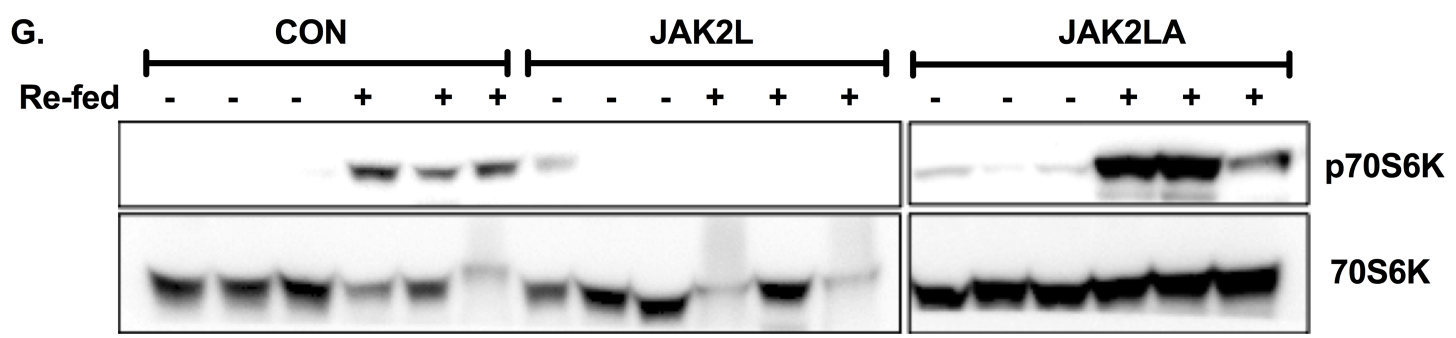

Figure 2: JAK2L mice are lipodystrophic and have a defective fasted-to-fed response in adipose tissue. (A.) Body weight in grams (g) of ad lib fed and 16-hour fasted control (CON), JAK2L, and JAK2LA mice. (B.) Percent body weight lost following 
a 16-hour fast. (C.) Percent lean and fast mass. Amount of (D.) epididymal and (E.) inguinal fat mass as a percent of total body weight. (F) H\&E staining of inguinal fat pads from 16-hour fasted mice. (G) Inguinal adipose levels of phosphorylated (T389) p70S6K (top) and total p70S6K (bottom) in 16-hour fasted (-) or 30-minute re-fed (+) as determined by Western blot. $\mathrm{N}=10-15(\mathrm{~A}$ and $\mathrm{B}), \mathrm{N}=12-17(\mathrm{C}), \mathrm{N}=5-7(\mathrm{D}$ and $\mathrm{E}) .{ }^{*} p<0.05$, ${ }^{* *} p<0.01,{ }^{* * * *} p<0.0001$ by 1 Way (B and $E$ ) or 2Way (A and C) ANOVA. 


\section{Figure 3}

A.

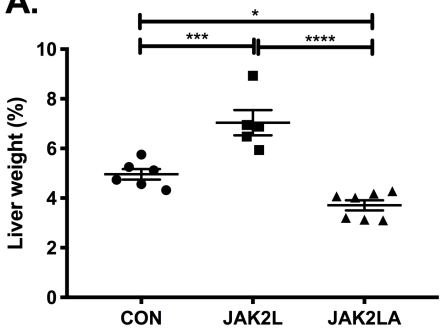

D.

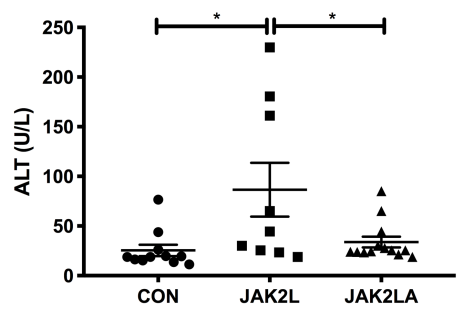

G.

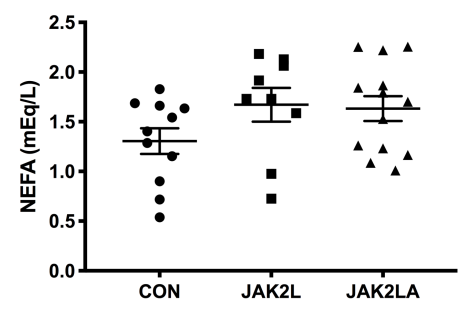

I.

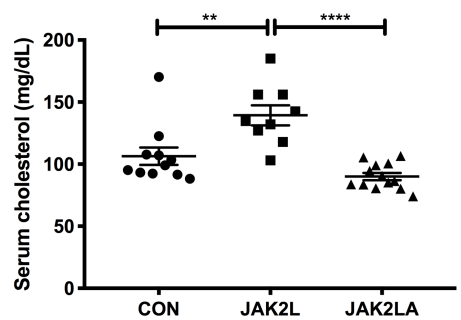

B.

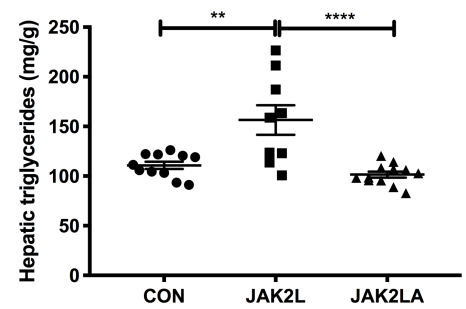

E.

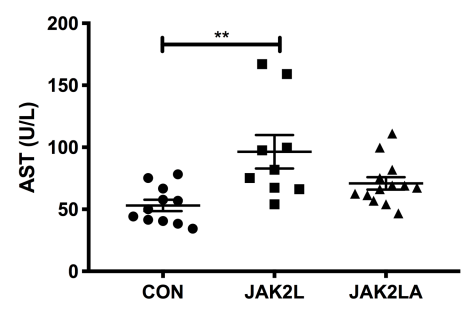

H.

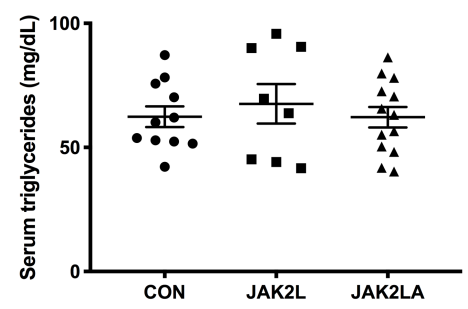

J.

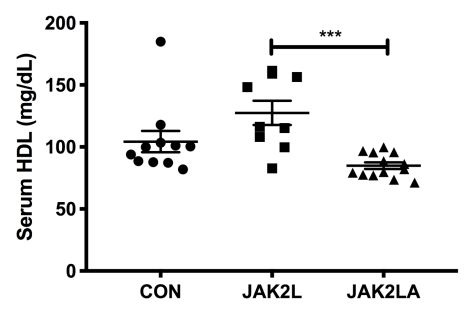

C.

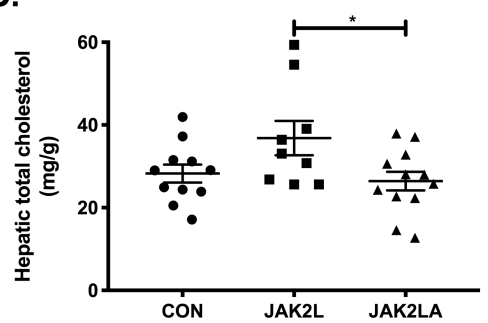

F.

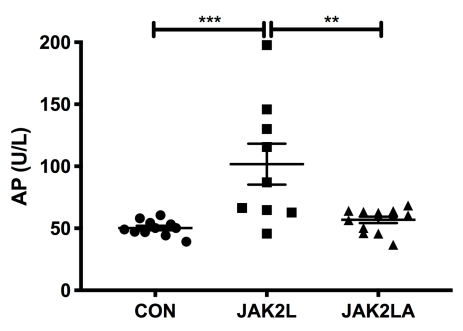

K.

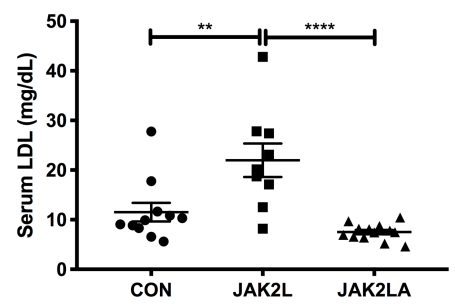

Figure 3: Loss of hepatocyte Jak2 promotes liver damage and dyslipidemia in an adipocyte Jak2-dependent manner. (A) Liver weight as a percent of total body weight in 16-hour fasted control (CON), JAK2L, and JAK2LA mice. Hepatic (A.) triglycerides and (C.) total cholesterol levels in 16-hour fasted mice. (D). Alanine aminotransferase (ALT), 
(E.) Aspartate aminotransferase (AST), (F.) Alkaline phosphatase (AP), (G.) Nonesterified fatty acids (NEFA), (H.) Triglycerides, (I.) Cholesterol, (J.) High density lipoprotein (HDL), and (K.) Low density lipoprotein levels in 16-hour fasted serum. $N=5-7$ (A), $N=9-12$ (B and C), N=9-13 (D-K). ${ }^{*} p<0.05,{ }^{* *} p<0.01,{ }^{* * *} p<0.001,{ }^{* * * *} p<0.0001$ by 1Way ANOVA. 
Figure 4

A
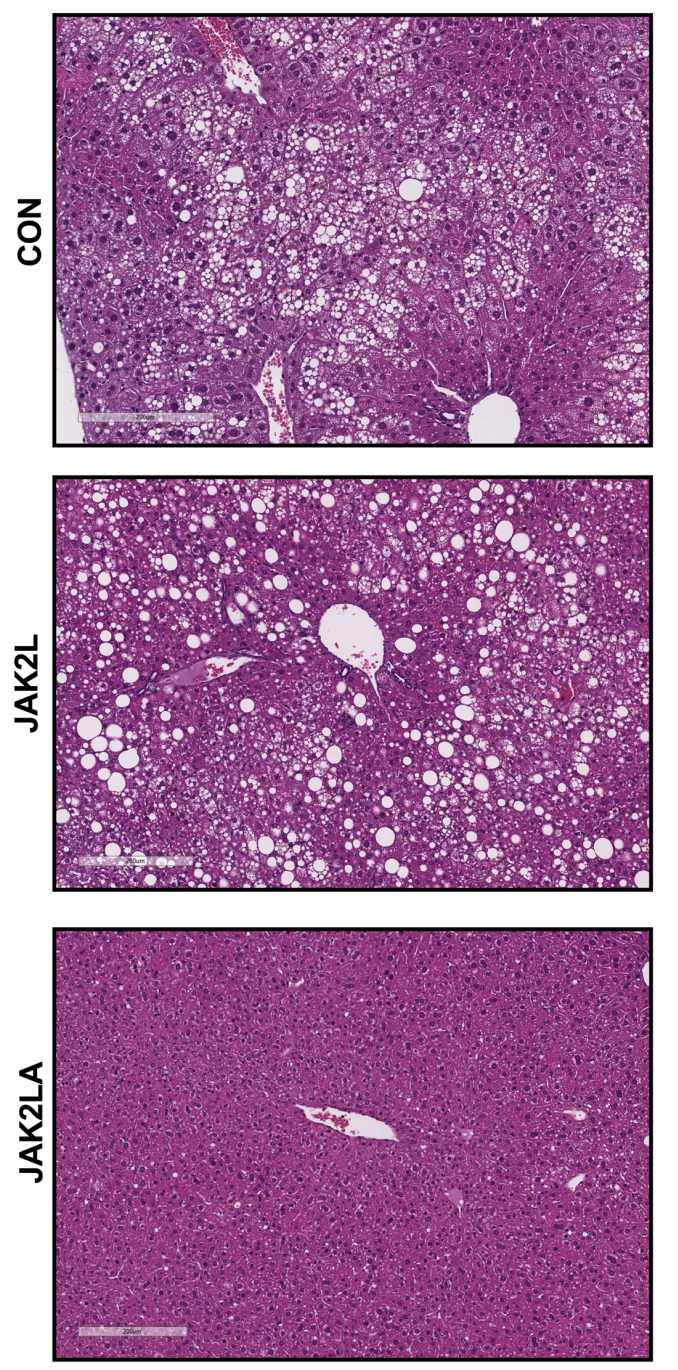

C.

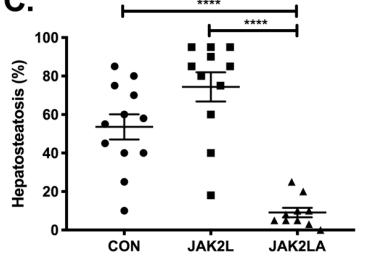

E.

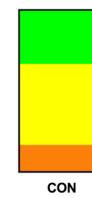

믐 $33.33 \%$ None

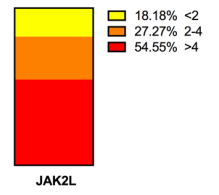

B.
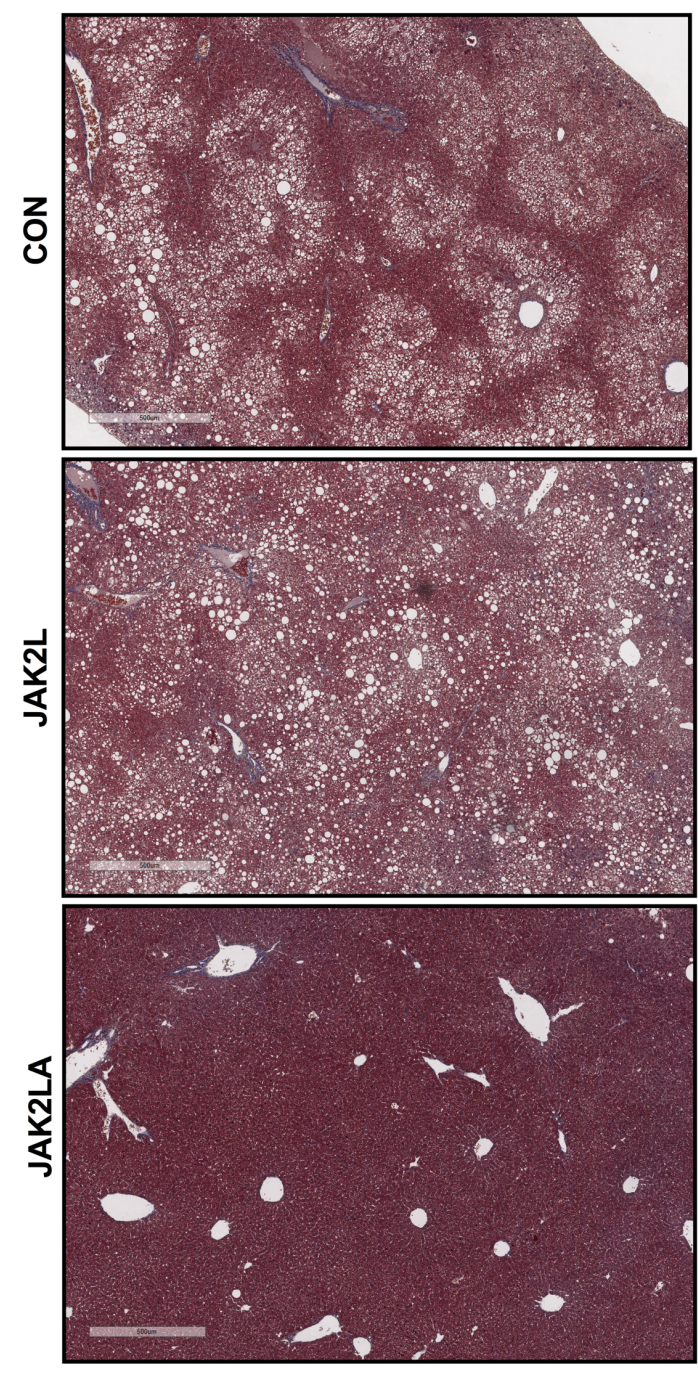

D.
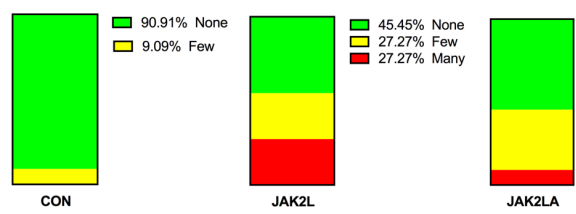

믐 $34.55 \%$ None
36.36\% Few
9.09\% Many

F.

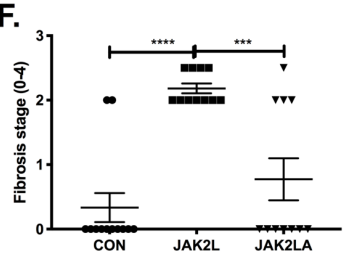


Figure 4: Loss of hepatocyte Jak2 promotes NAFLD and NASH in an adipocyte Jak2-dependent manner. (A.) H\&E and (B.) Trichrome staining of liver sections from control (CON), JAK2L, and JAK2LA mice. (C.) Percent hepatosteatosis, (D.) Ballooning, and (E.) Inflammatory loci observed in liver sections. (F.) Fibrosis staging score. (G.) Brunt staging score. $\mathrm{N}=10-12 .{ }^{* * *} p<0.001,{ }^{* * * *} p<0.0001$ by 1 Way ANOVA. 


\section{Figure 5}

A.

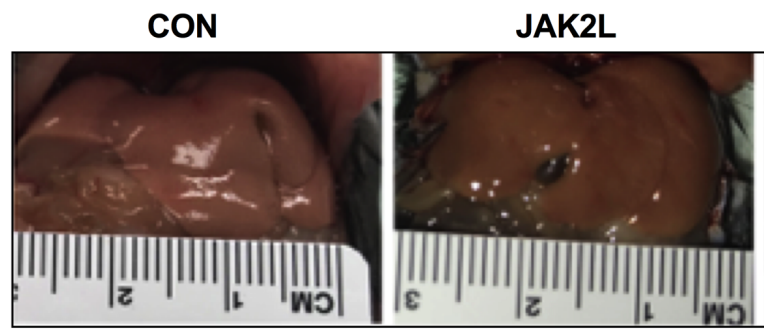

C.
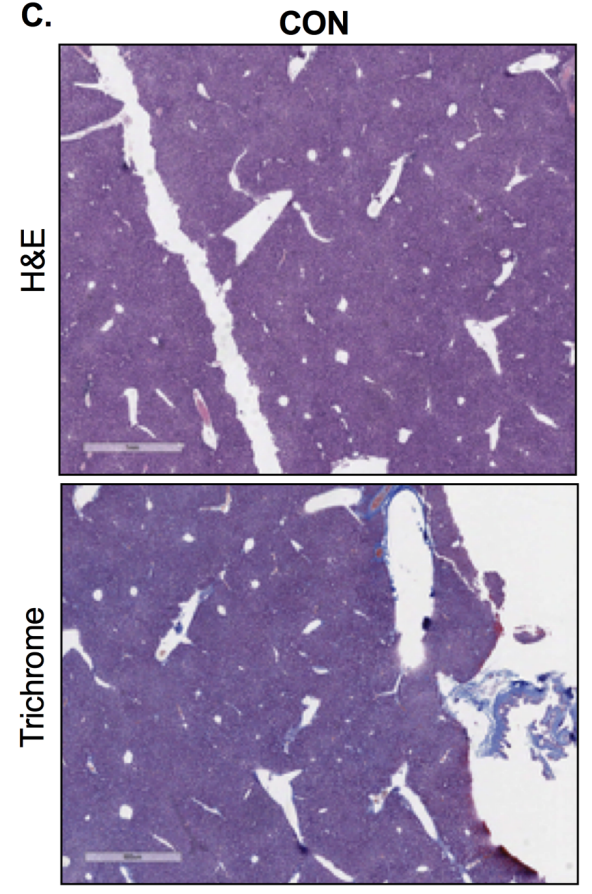

E.

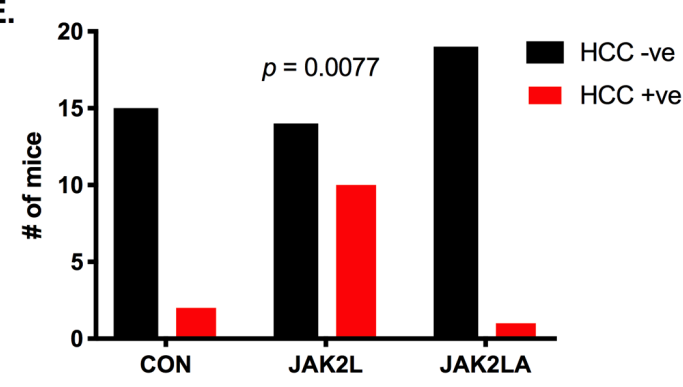

B.

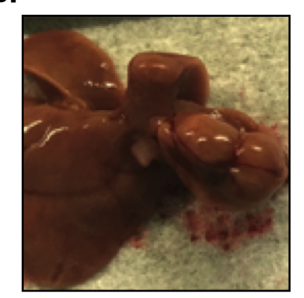
JAK2L

D.
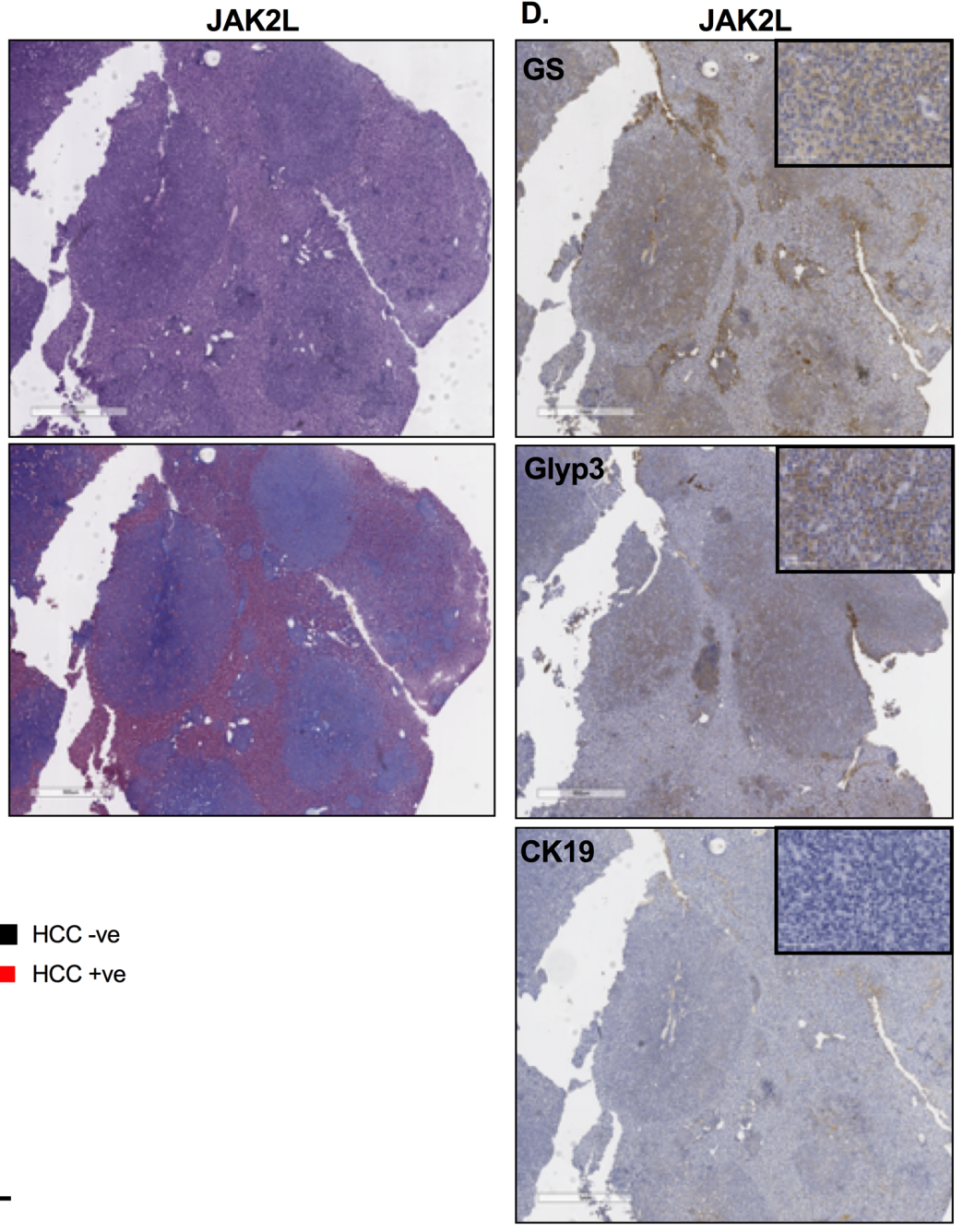

Figure 5: loss of hepatocyte Jak2 promotes HCC in an adipocyte Jak2-dependent manner. (A.) Pictures of gross livers from control (CON), JAK2L, and JAK2LA mice. (B.) Liver nodules on a JAK2L liver. (C.) H\&E and Trichrome staining of liver sections 
from CON mice and JAK2L nodules. (D.) Immunohistochemistry (high magnification shown in inset) of sections from JAK2L liver nodules stained with anti-Glutamine Synthetase (GlutSyn), anti-Glypican3 (Glyp3), and CK19. (E.) Contingency evaluation of $\mathrm{HCC}$ incidence showing the number of mice with $\mathrm{HCC}$ negative (HCC -ve) and positive $(\mathrm{HCC}+\mathrm{ve})$ tumors, $\mathrm{N}=17-24$. $P$ value determined by Chi-square testing. 
Figure 6

A.

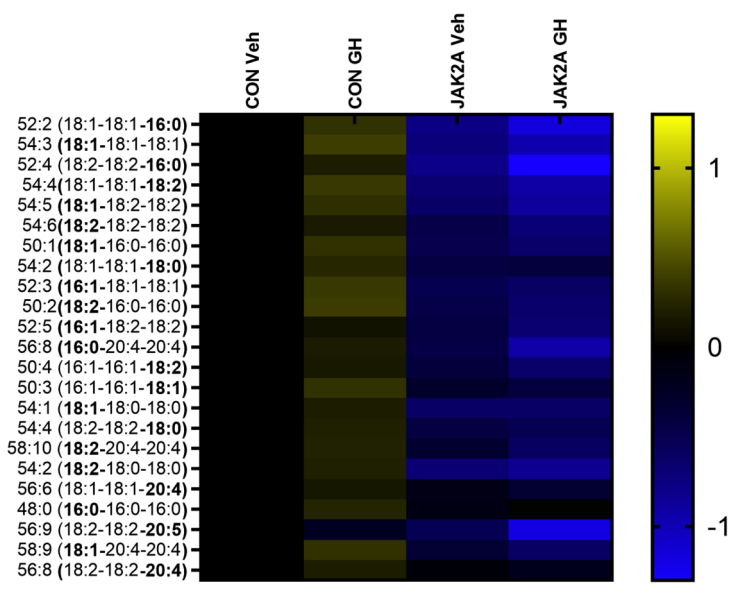

c.

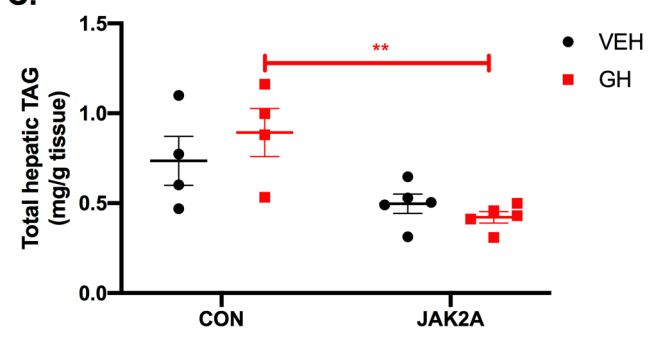

E.

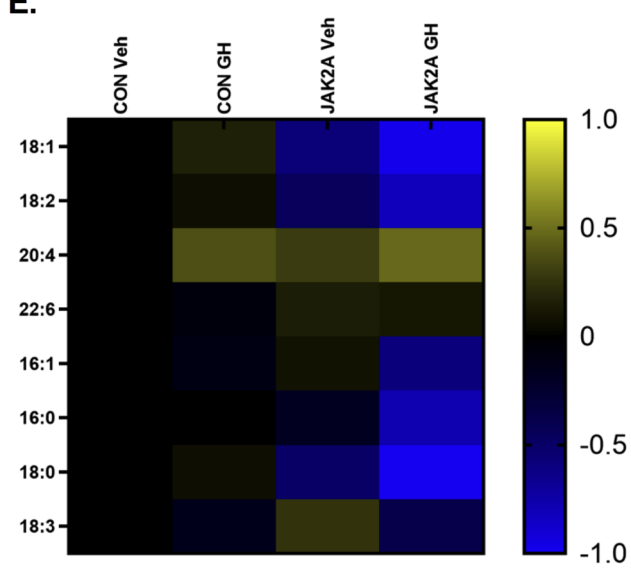

G.

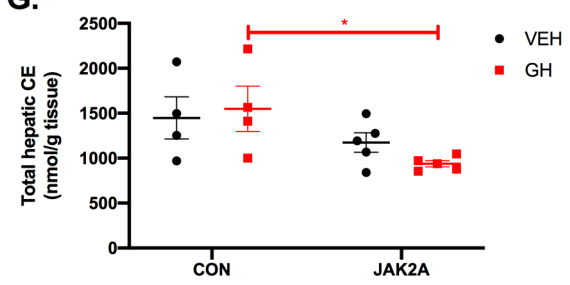

B.

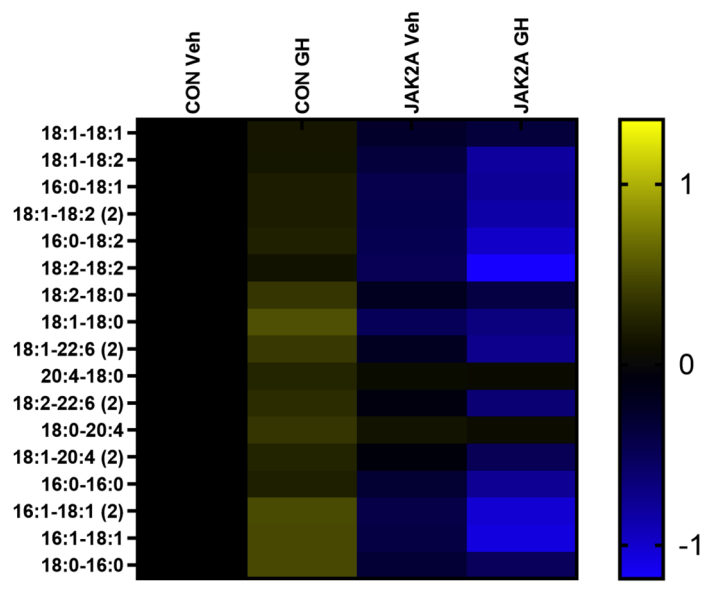

D.

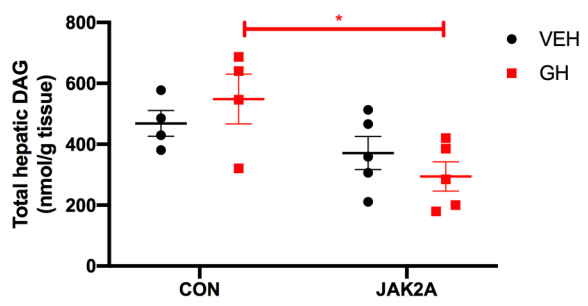

F.

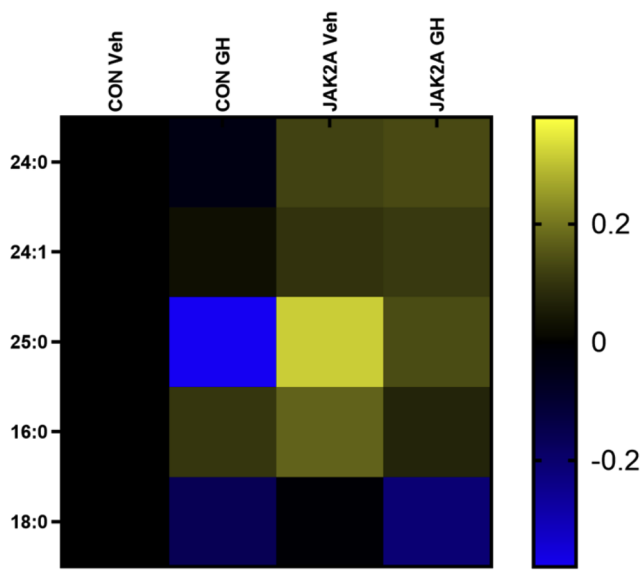

H.

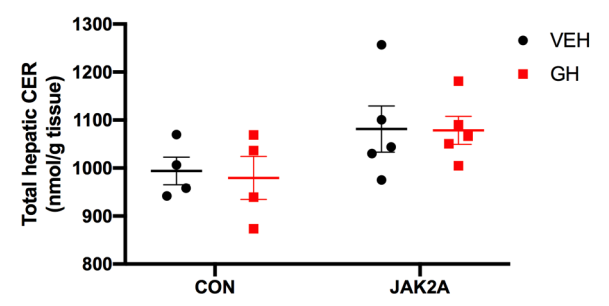


Figure 6: Growth hormone treatment induces hepatic lipid deposition via adipocyte

JAK2. Lipidomics heat maps of individual hepatic (A.) Triacylglycerol (TAG), (B.) Diacylglycerol (DAG), (E.) Cholesterol ester (CE), and (F.) Ceramide (CER) species in vehicle (Veh)- or Growth hormone (GH)-treated control (CON) and JAK2A mice. Total hepatic (C.) TAG, (D.) DAG, (G.) CE, and (H.) CER levels. ${ }^{*} p<0.05 .{ }^{* *} p<0.01$ by 2 Way ANOVA. For lipidomic heat maps, all values of individual lipid species are expressed as the log2 ratio to vehicle-treated CON mice and visualized by the log2 scale to the right of the heat map. $\mathrm{N}=4-5$. 


\section{Figure 1}

A.

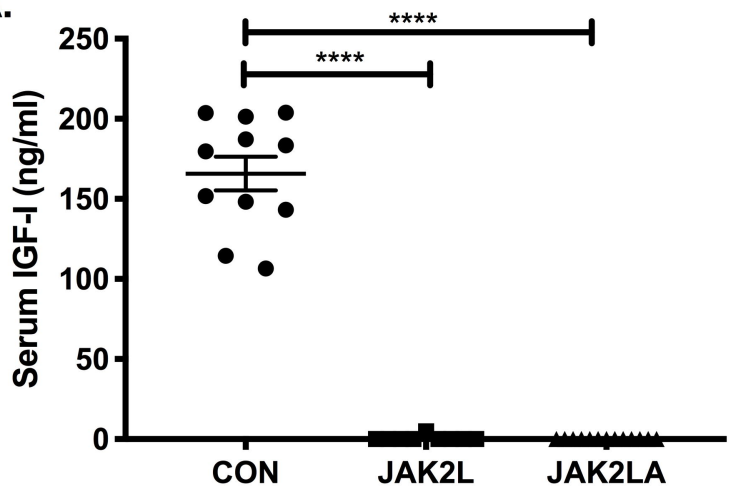

c.

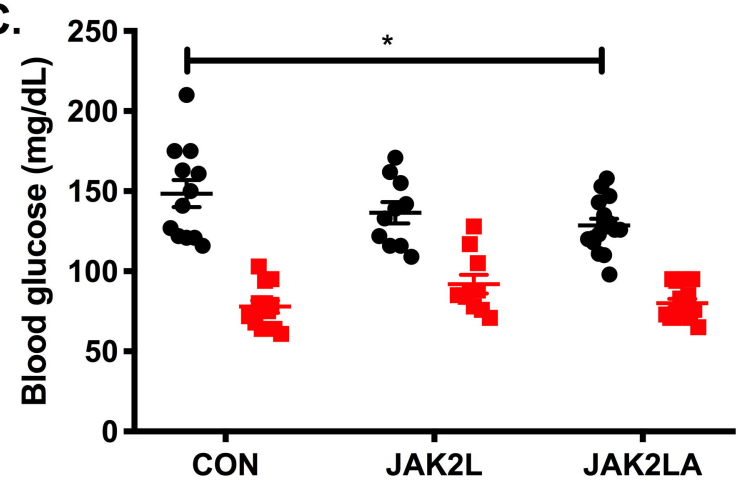

E.

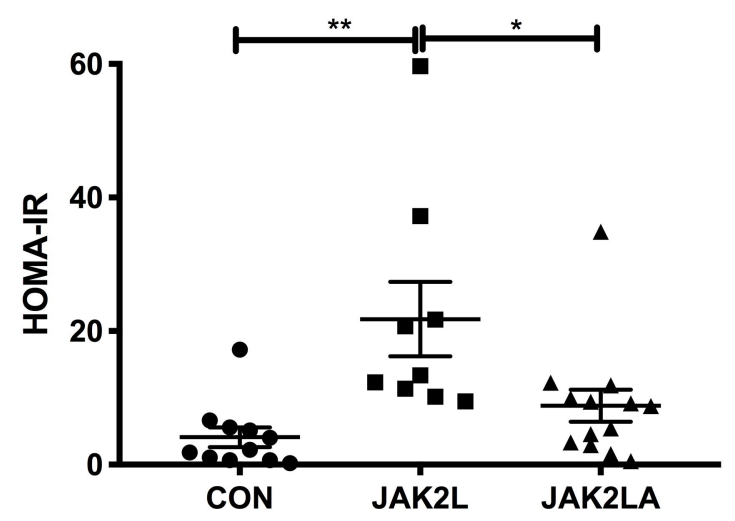

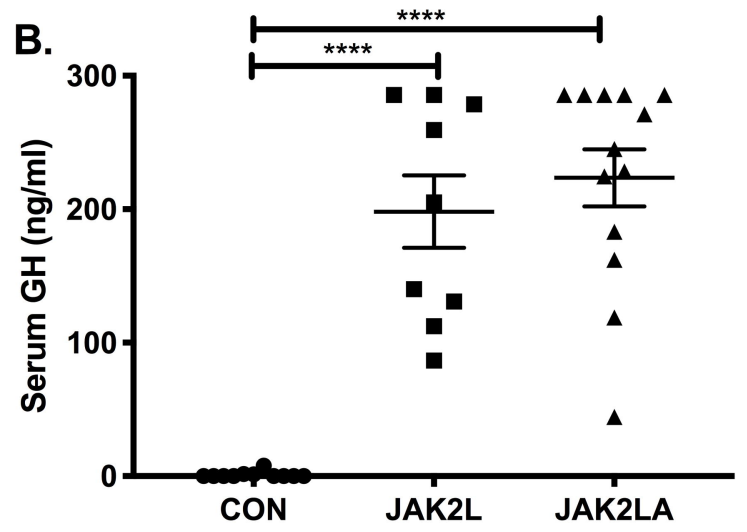

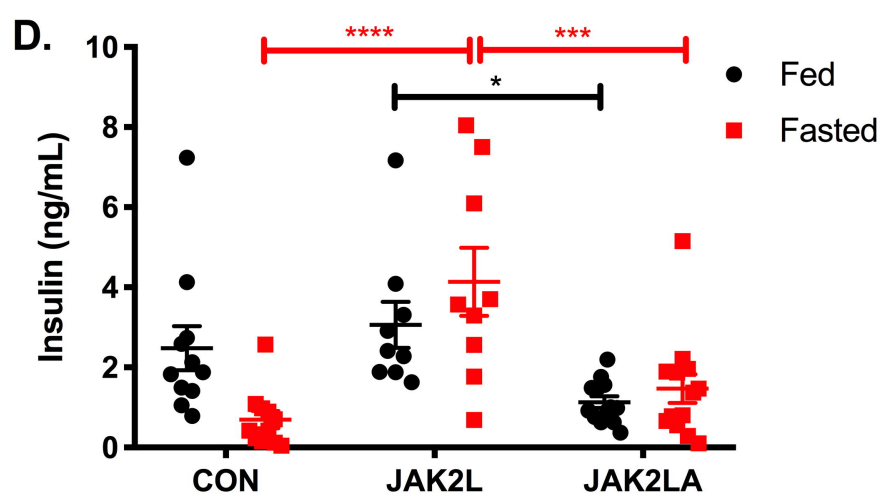

F.

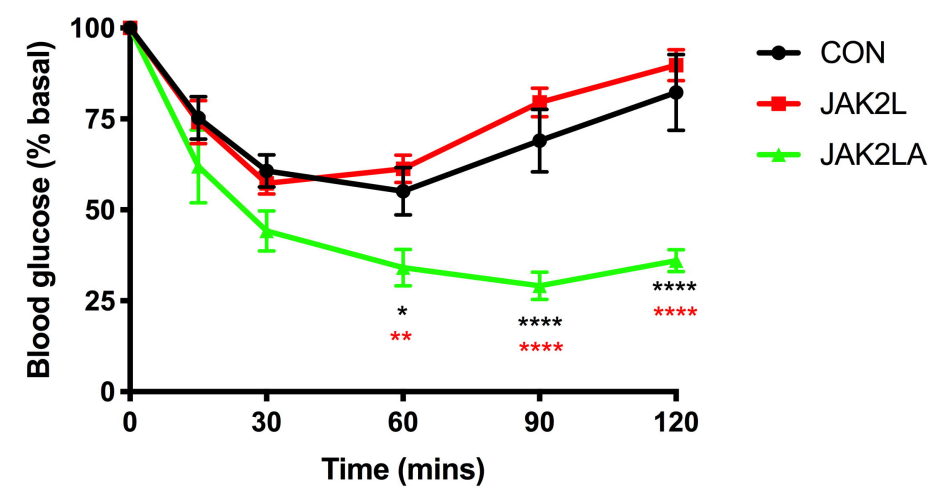


Figure 2

A.

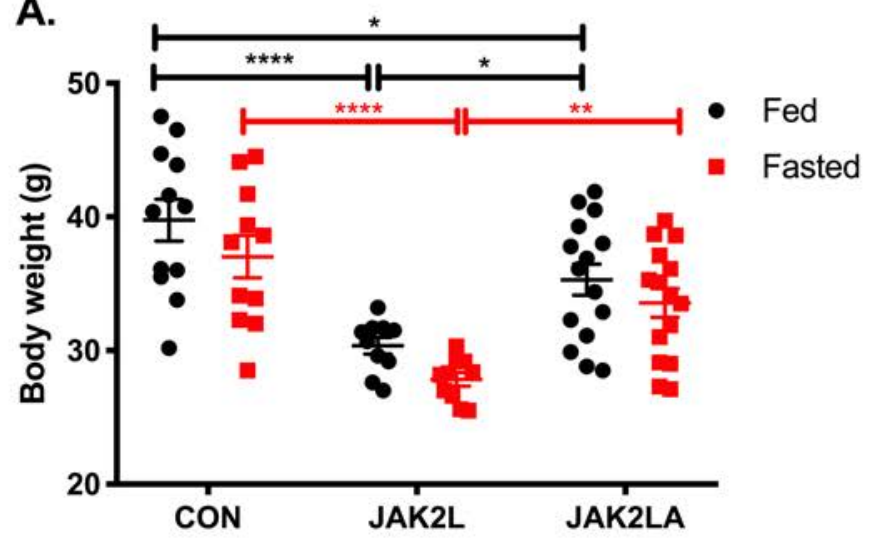

C.

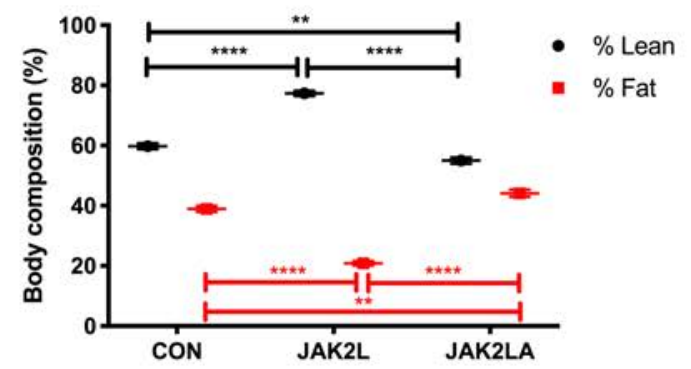

F.

CON

D.
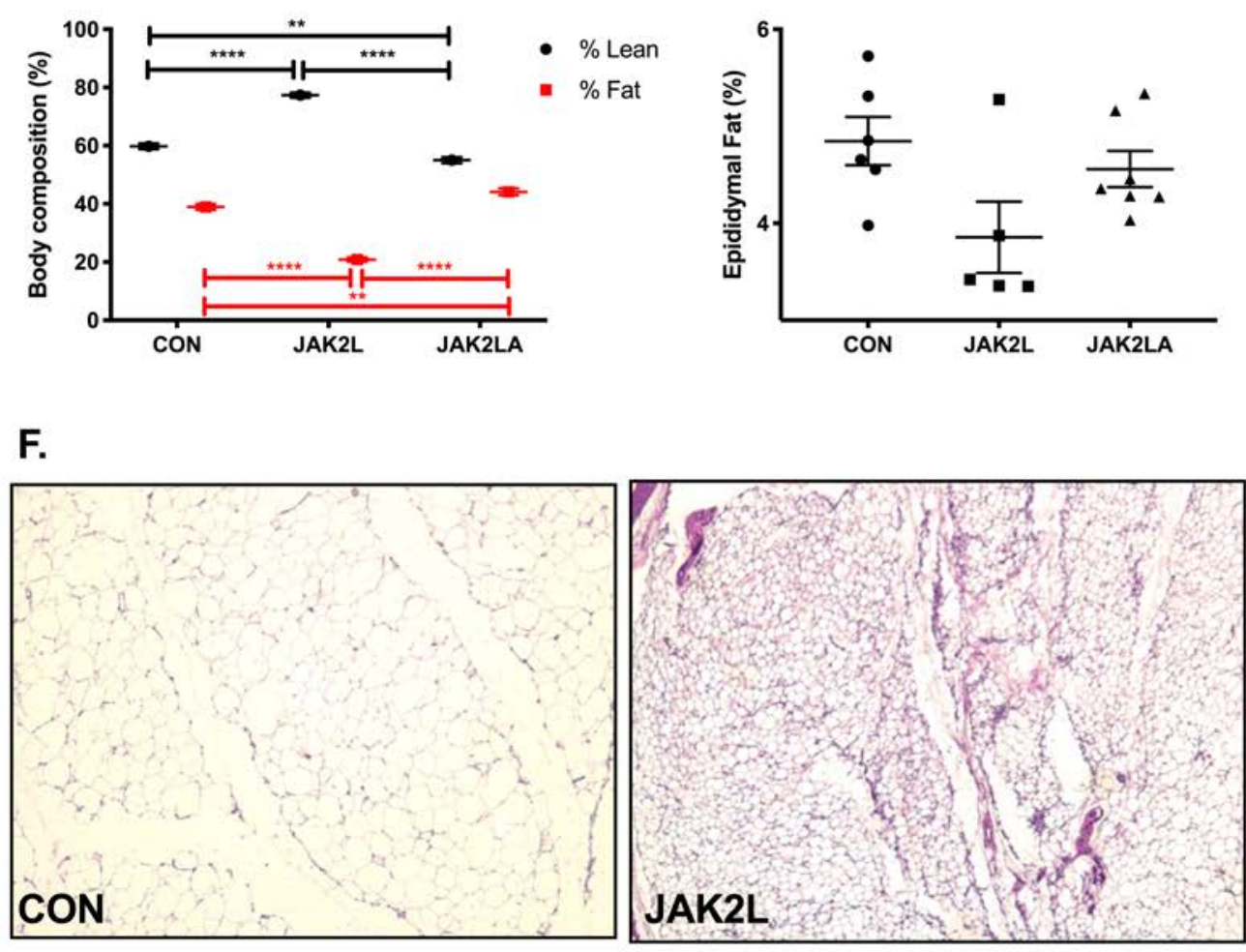

B.

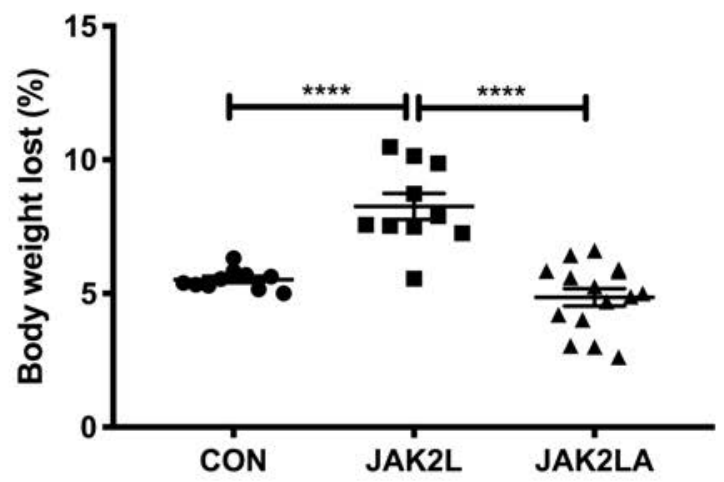

E.

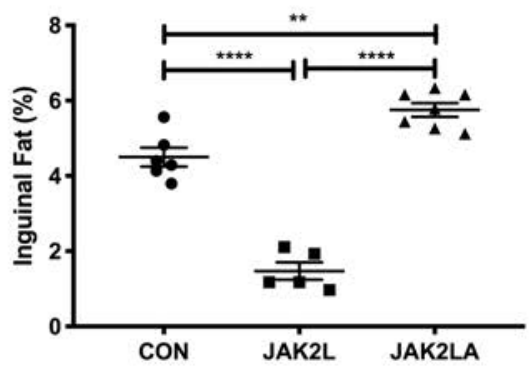

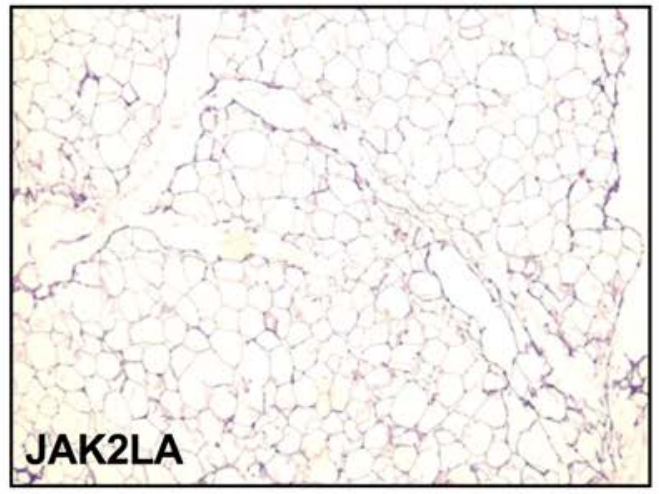

G.

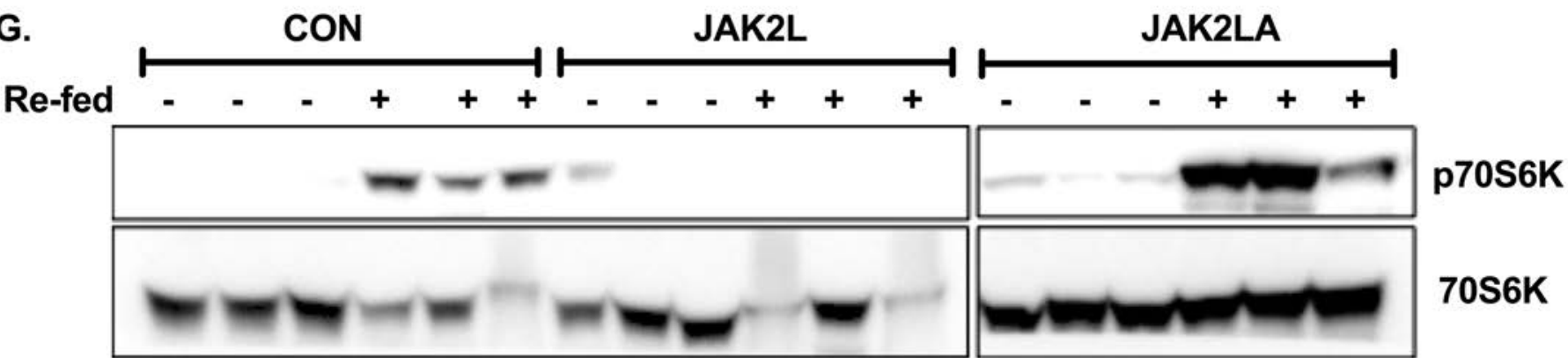


A.

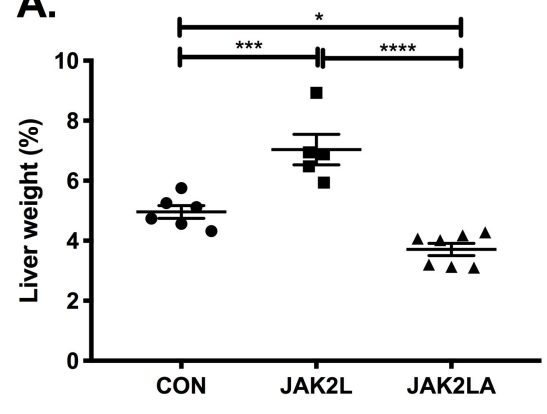

D.

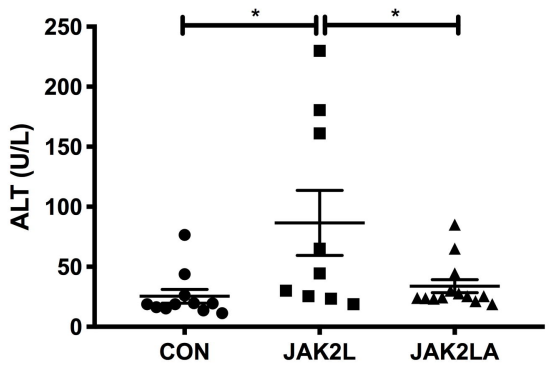

G.

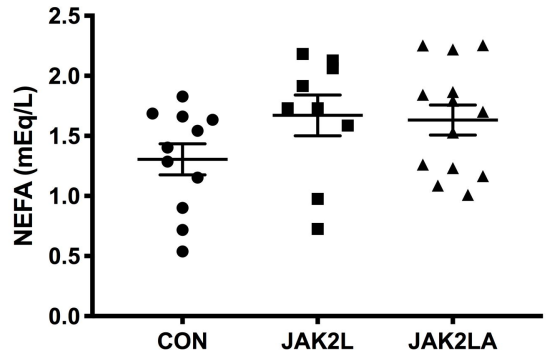

I.

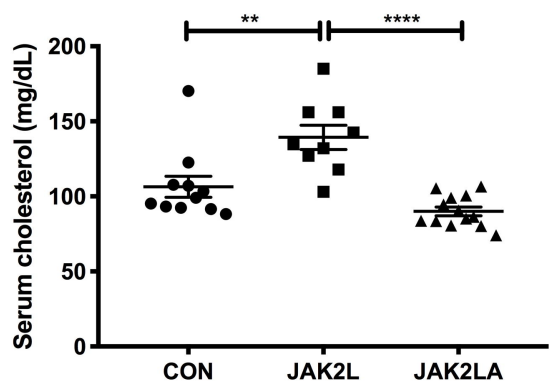

B.

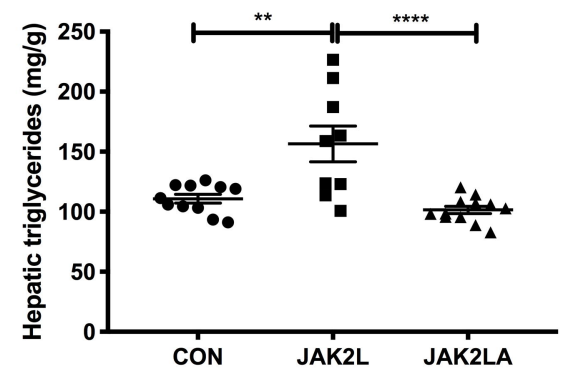

E.

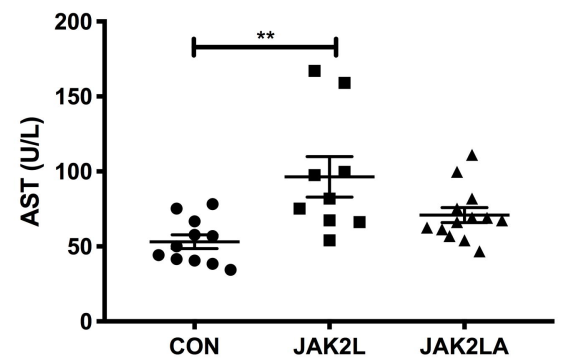

H.

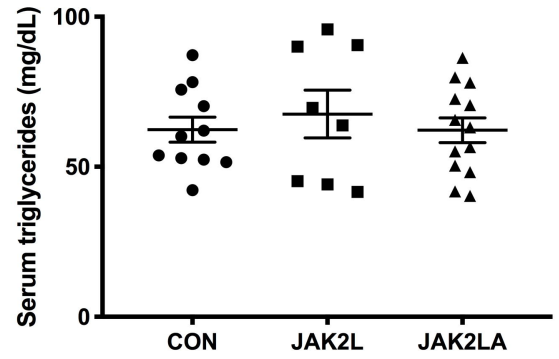

J.

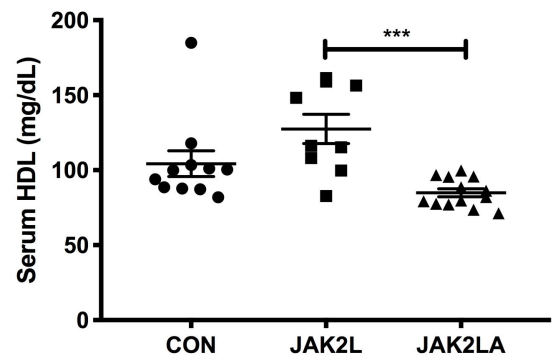

c.

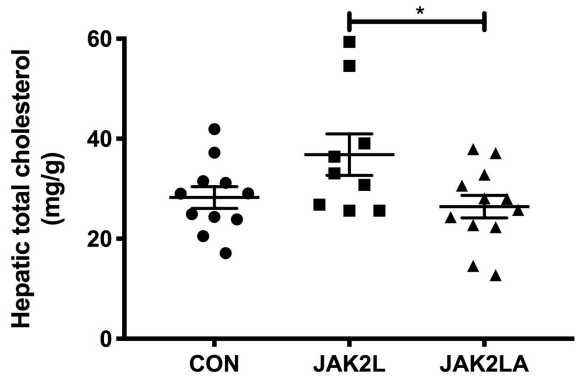

F.

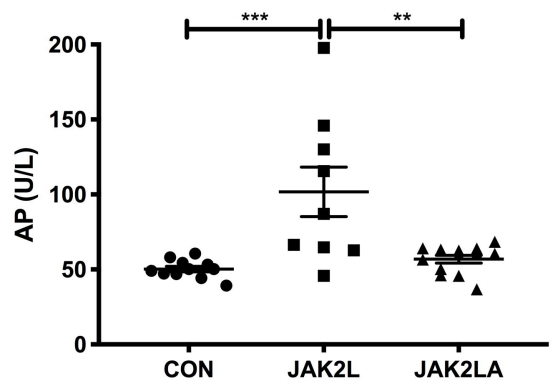

K.

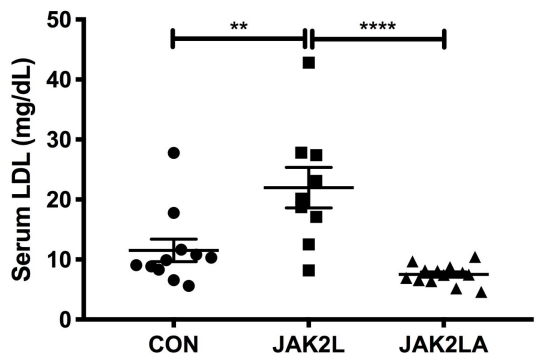


A.
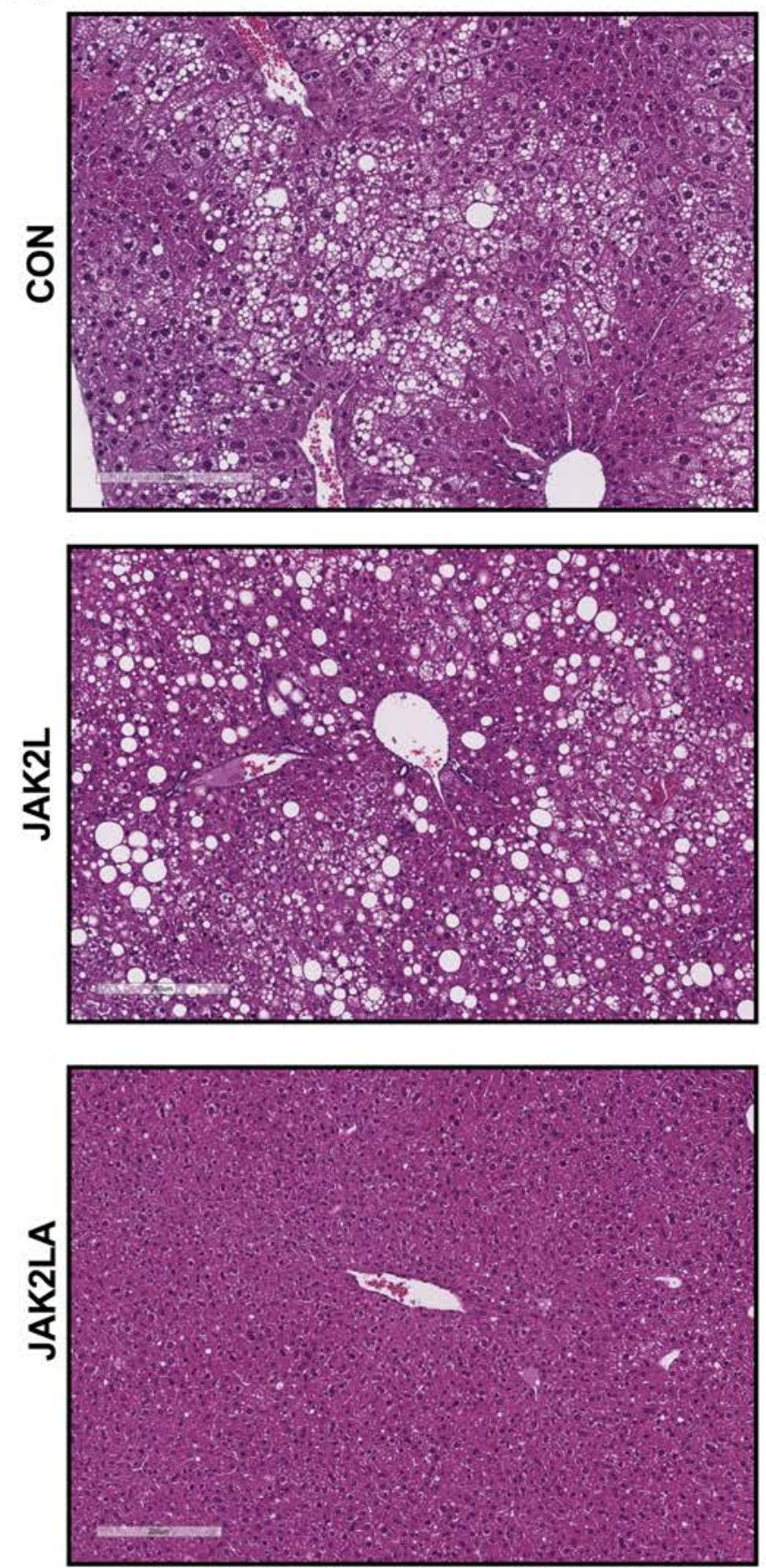

C.

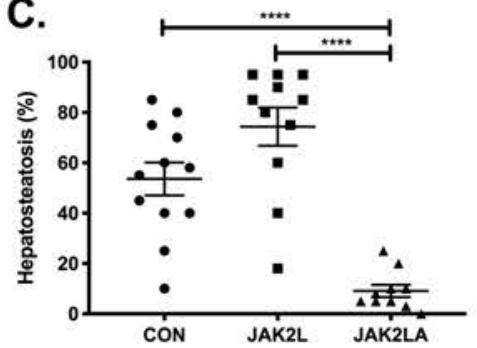

E.

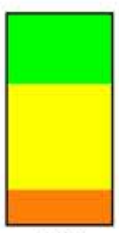

ㅁ $33.33 \%$ Non $50.00 \%<2$

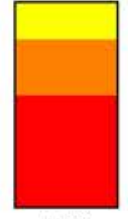

口 $18.18 \%<2$ 口 $54.55 \%>4$

B.
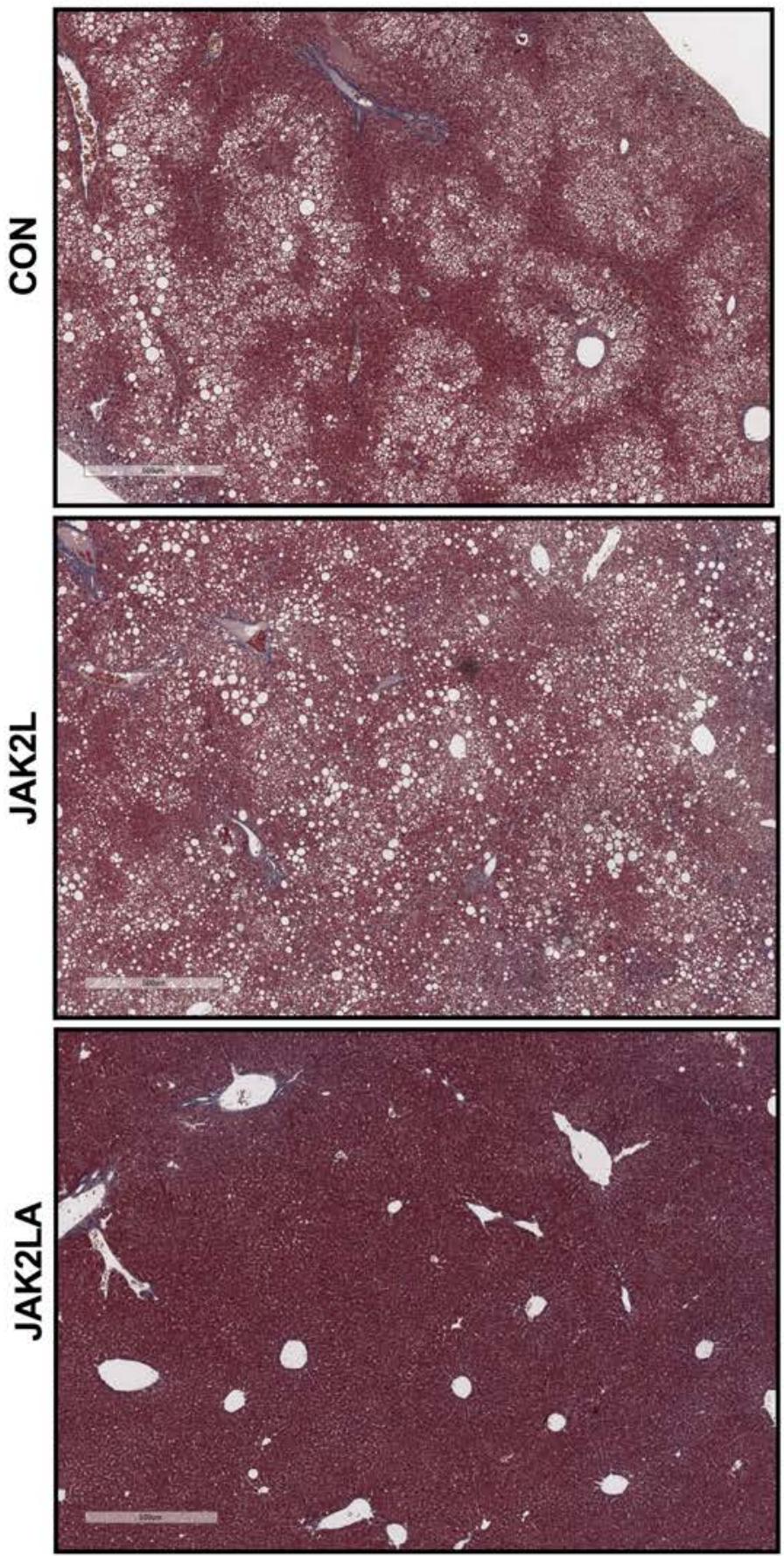

D.

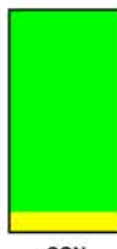

90.91\% Non $\square 9.09 \%$ Few

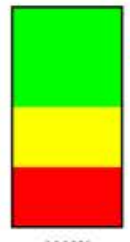

$45.45 \%$ None
$27.27 \%$ Few 吕 $27.27 \%$ Few

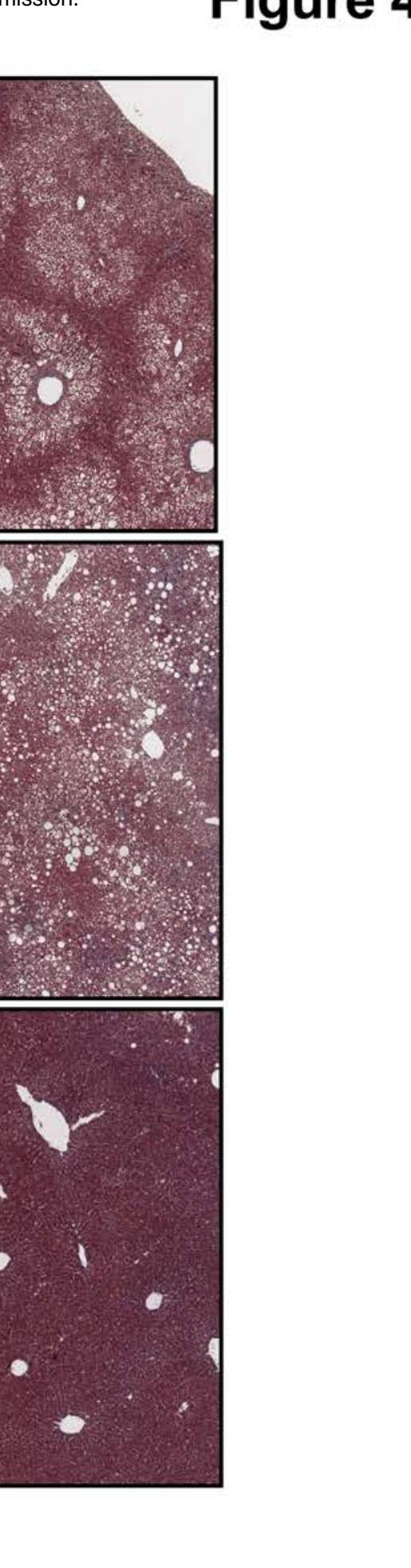

Fil 


\section{Figure 5}

A.

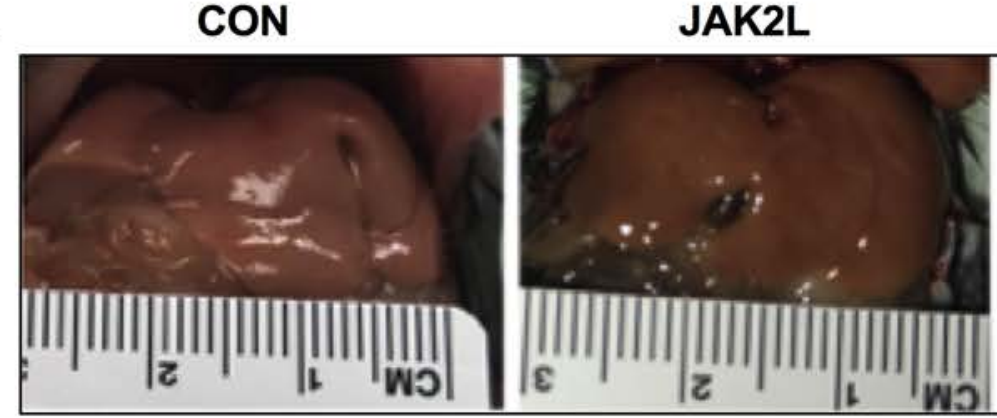

C.

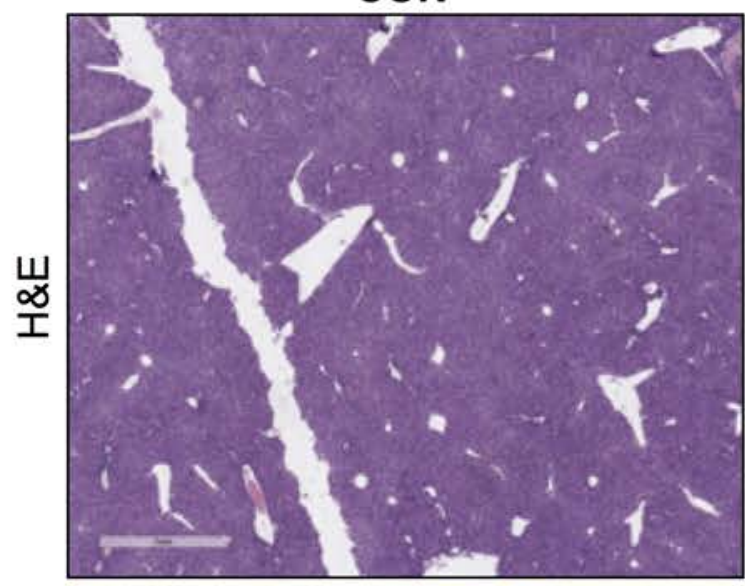

을 을
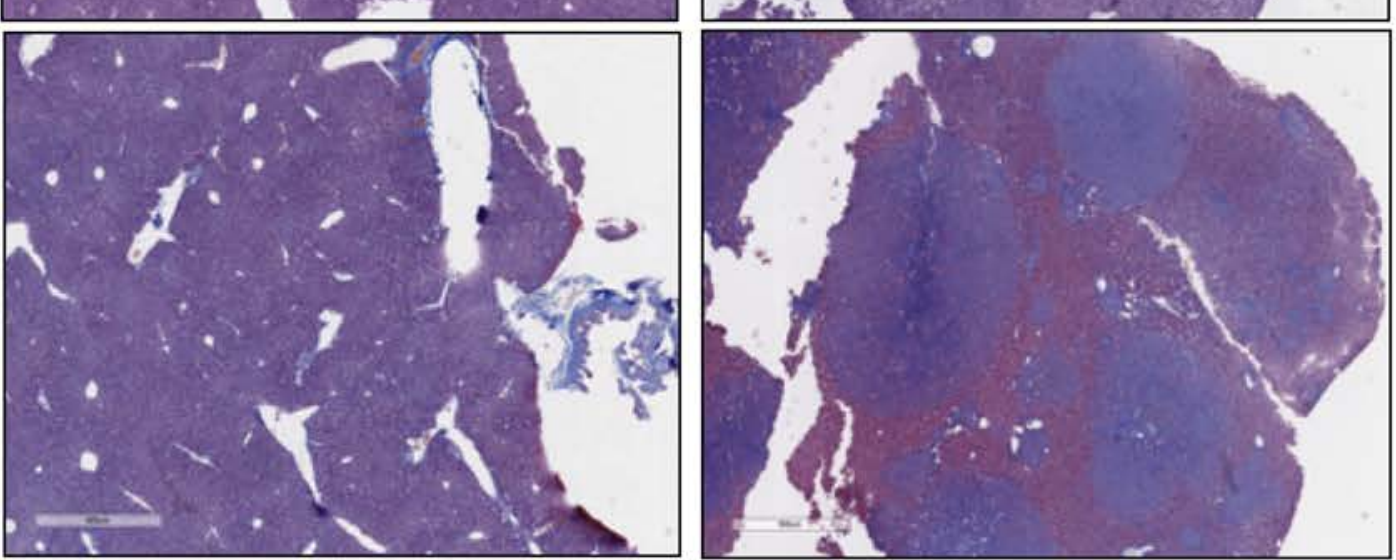

E.

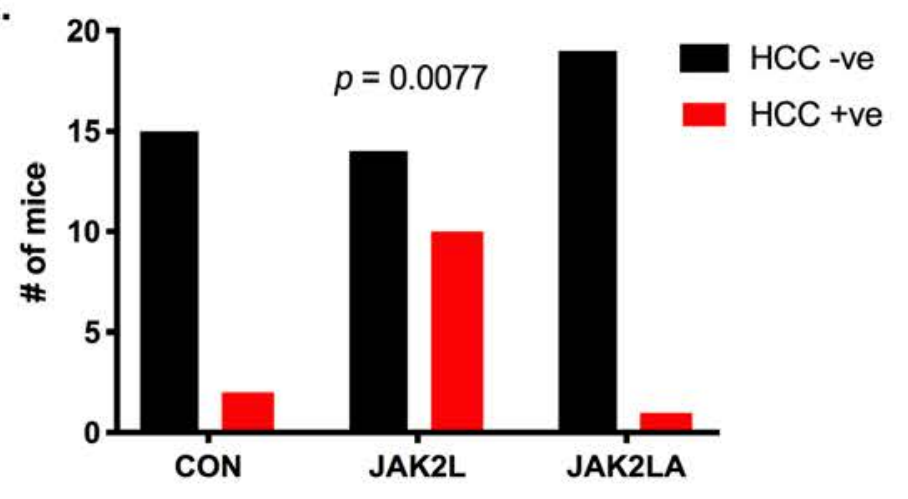

JAK2LA

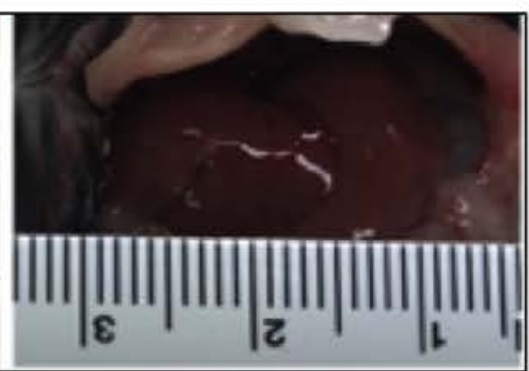

B.

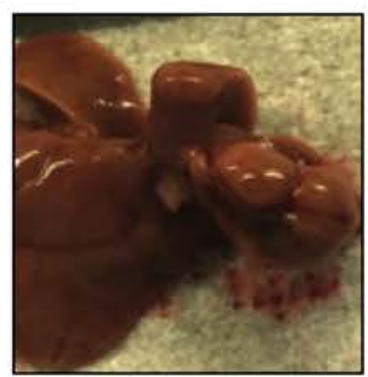

D.
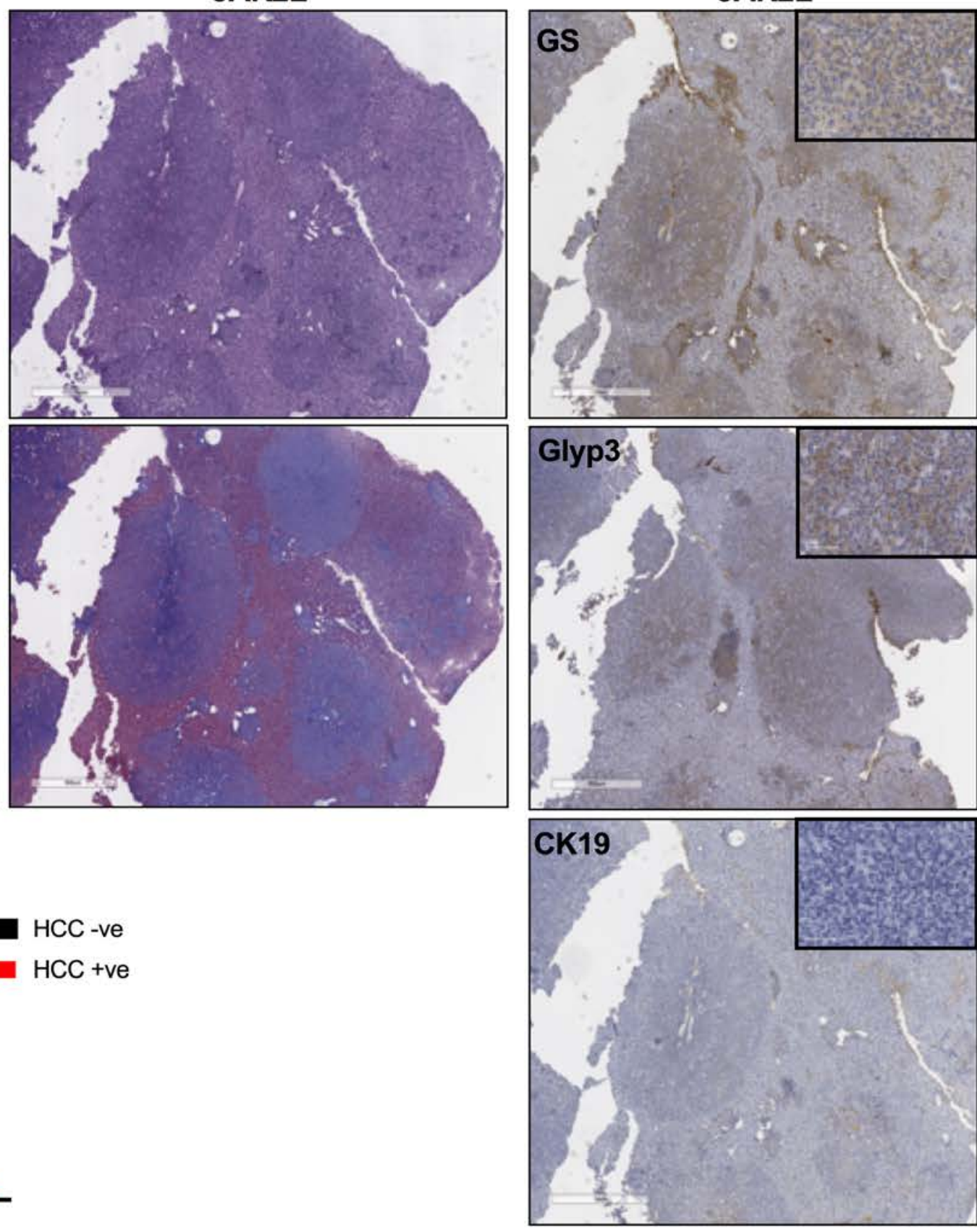
A.

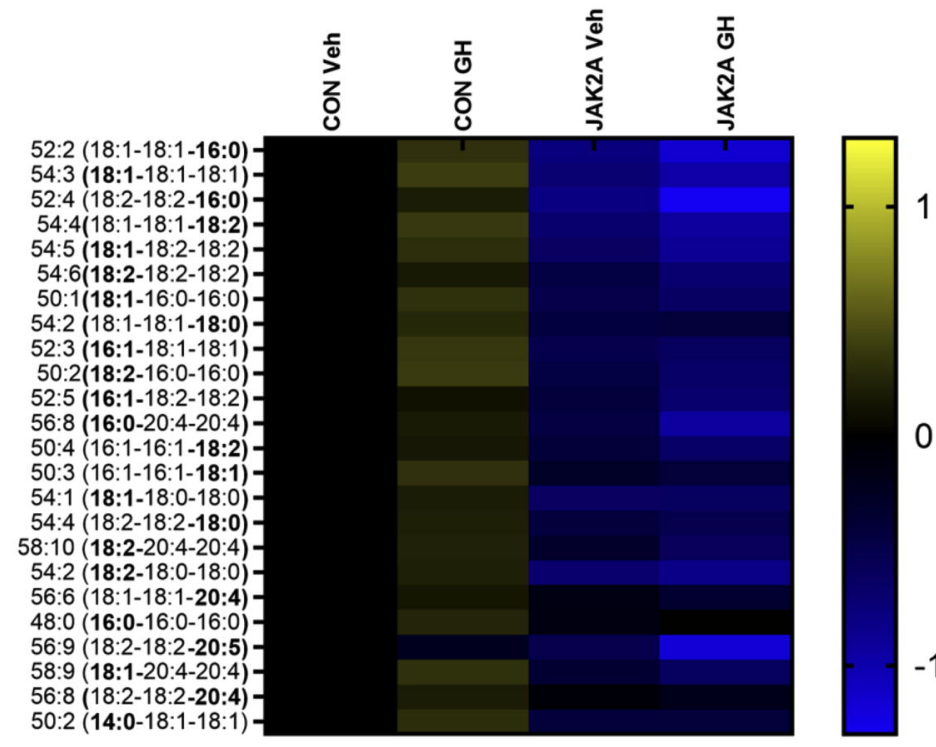

C.

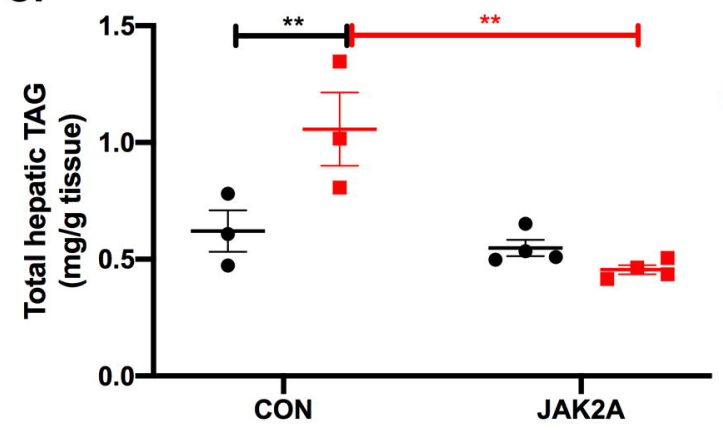

E.

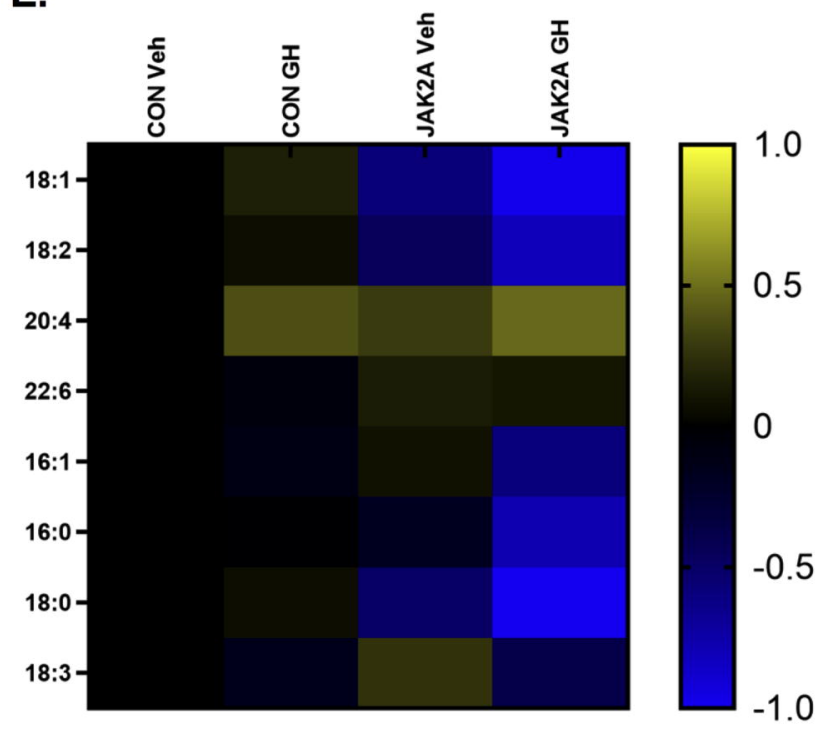

B.

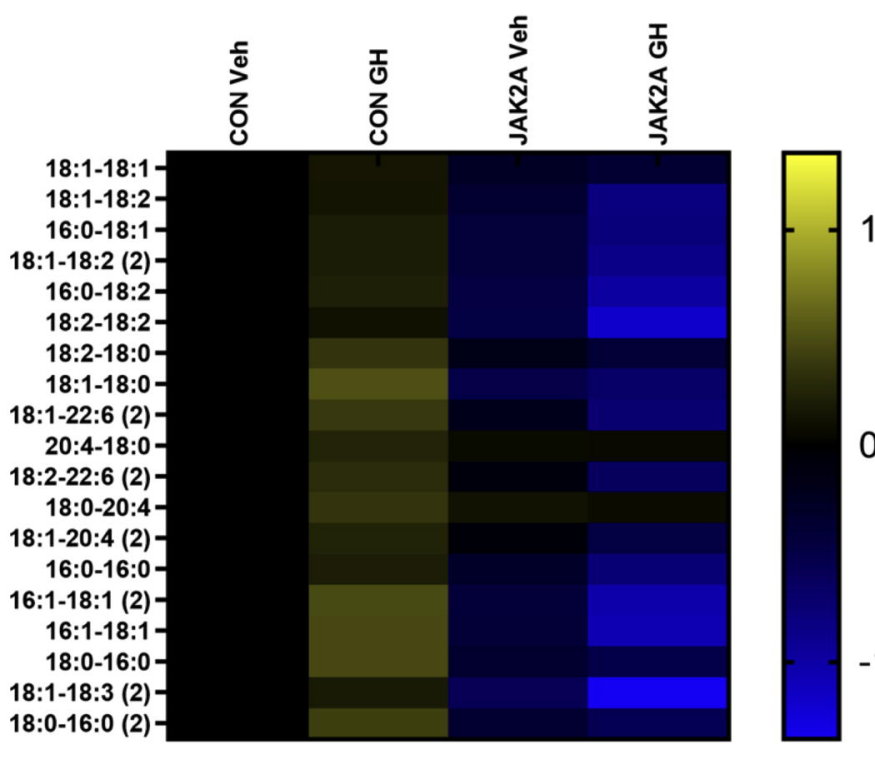

D.

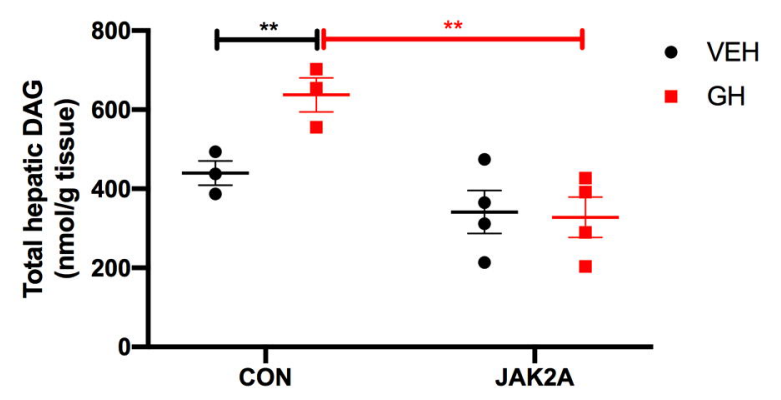

F.

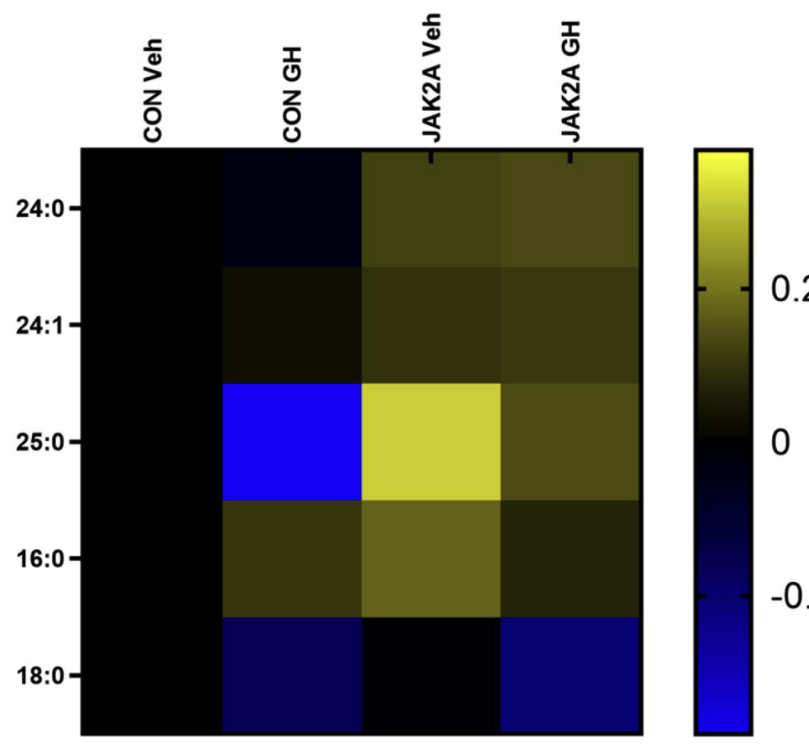

H.
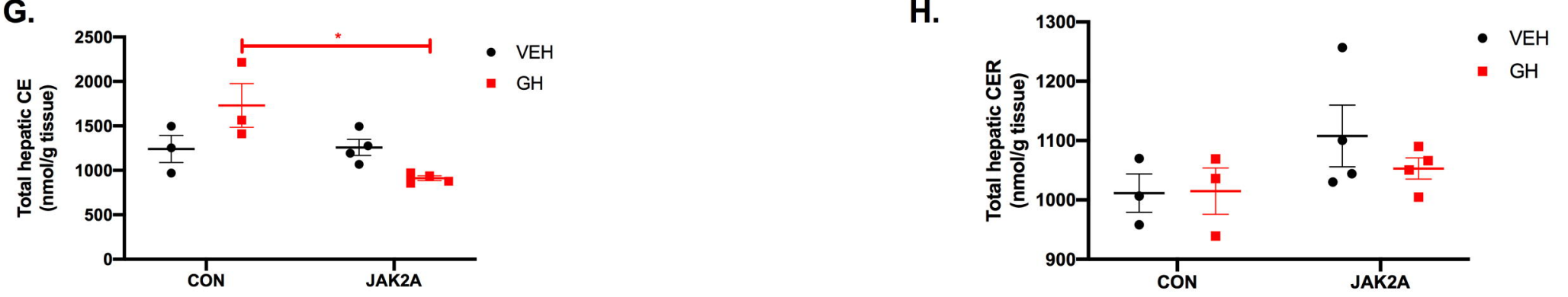